\title{
Plant Phospholipases D and C and Their Diverse Functions in Stress Responses
}

Yueyun Hong ${ }^{\mathrm{a}, \mathrm{c}, \mathrm{d}}$, Jian Zhao ${ }^{\mathrm{a}, \mathrm{c}, \mathrm{d}}$, Liang Guo ${ }^{\mathrm{a}, \mathrm{b}}$, Sang-Chul Kim ${ }^{\mathrm{b}}$, Xianjun Deng ${ }^{\mathrm{a}}$, Geliang Wang ${ }^{\mathrm{b}}$, Gaoyang Zhang ${ }^{\mathrm{a}}$, Maoyin $\mathrm{Li}^{\mathrm{b}}$, and Xuemin Wang ${ }^{\mathrm{b}, \mathrm{d}}$

${ }^{a}$ National Key Laboratory of Crop Genetic Improvement, Huazhong Agricultural University, Wuhan 430070, China

${ }^{\mathrm{b}}$ Department of Biology, University of Missouri, St. Louis, MO 63121, USA; Donald Danforth Plant

Science Center, St. Louis, MO 63132, USA

${ }^{\mathrm{c}}$ Authors contributed to the work equally.

${ }^{\mathrm{d}}$ Corresponding authors: National Key Laboratory of Crop Genetic Improvement, Huazhong

Agricultural University, Wuhan 430070, China; E-mail: hongyy@mail.hzau.edu.cn and

jianzhao@mail.hzau.edu.cn, and Department of Biology, University of Missouri, St. Louis, MO

63121, USA; Donald Danforth Plant Science Center, St. Louis, MO 63132, USA; Tel: (314) 587-1419;

E-mail: swang@danforthcenter.org

\begin{abstract}
Phospholipases D (PLD) and C (PLC) hydrolyze the phosphodiesteric linkages of the head group of membrane phospholipids. PLDs and PLCs in plants occur in different forms: the calcium-dependent phospholipid binding domain-containing PLDs (C2-PLDs), the plekstrin homology and phox homology domain-containing PLDs (PX/PH-PLDs), phosphoinositide-specific PLC (PI-PLC), and non-specific PLC (NPC). They differ in structures, substrate selectivities, cofactor requirements, and/or reaction conditions. These enzymes and their reaction products, such as phosphatidic acid (PA), diacylglycerol (DAG), and inositol polyphosphates, play important, multifaceted roles in plant response to abiotic and biotic stresses. Here, we review biochemical properties, cellular effects, and physiological functions of PLDs and PLCs, particularly in the context of their roles in stress response along with advances made on the role of PA and DAG in cell signaling in plants. The mechanism of actions, including those common and distinguishable among different PLDs and PLCs, will also be discussed.
\end{abstract}

\section{KEYWORDS}

PLD, PLC, PA, DAG, $\mathrm{IP}_{3}, \mathrm{IP}_{6}$, vesicular trafficking, cytoskeleton, lipid-protein interaction, hormone signaling, plant-pathogen interaction, defense response, membrane remodeling, lipid hydrolysis 


\section{CONTENTS}

1. Introduction

2. Phospholipase D (PLD)

2.1. Classification and domain structures

2.2. Catalytic properties and regulation of PLD activities

2.3. Subcellular localization and tissue distribution

2.4. Cellular and physiological functions

2.4.1. Distinguishable functions of different PLDs in stress responses

2.4.2. Different PLDs in common physiological processes with different modes of action

2.4.3. PLDs involved in plant defense responses

2.4.3.1. PLD $\alpha 1$ in plant-microbe interactions

2.4.3.2. PLD $\beta 1$ in plant response to bacterial and fungal pathogens

2.4.3.3. PLD $\delta$ in defense against non-host penetration fungi

2.4.3.4. Other PLDs potential in plant defense responses

2.4.3.5. PLD involvement in plant-virus interactions

2.5. Mechanisms of PLD effects on cellular functions

2.5.1. Production of the lipid mediator phosphatidic acid (PA)

2.5.2. PLD interaction with proteins

2.5.3. PLD regulation of actin/microtubule cytoskeletons

2.5.3.1. PLD $\beta 1$ interacts with actin cytoskeleton

2.5.3.2. PLD $\delta$ interacts with microtubules

2.5.3.3. Interactions of other PLDs with cytoskeletons

2.5.4. PLD regulation of vesicular trafficking

2.5.5. Lipid remodeling and changing membrane lipid composition

2.5.6. Lipid degradation and membrane deterioration under severe stress

3. Phospholipase C (PLC)

3.1. Non-specific phospholipase C (NPC) hydrolyzing common membrane phospholipids

3.1.1. Classification and domain structures

3.1.2. Substrate preference and regulation of NPC activities

3.1.3. Expression patterns and subcellular localization

3.1.4. Cellular and physiological functions

3.1.4.1. Lipid remodeling and plant response to phosphate deprivation

3.1.4.2. Osmotic and salt stress

3.1.4.3. Hormone responses

3.1.5. Mechanisms of NPC actions: DAG functions

3.2. PI-PLC: Phosphoinositide-specific PLCs

3.2.1. Classification and domain structures

3.2.2. Catalytic properties and regulation

3.2.3. Expression patterns and subcellular localization

3.2.4. Cellular and physiological functions

3.2.4.1. Vesicle trafficking and pollen growth mediated by $\mathrm{PIP}_{2}$

3.2.4.2. Gravitropic and hormone responses

3.2.4.3. Cytoskeletal organization and stress tolerance 


\subsubsection{Mechanisms of PI-PLC actions}

4. PA as lipid mediators and growth regulator

4.1. PA production under stress and PA molecular species

4.2. PA interaction with proteins and effects of the interactions

4.2.1. PA modulation of enzyme activity

4.2.2. PA interaction with proteins regulating cytoskeleton dynamics

4.2.3. PA modulation of subcellular associations of proteins

4.2.3.1. Tethering protein to membrane

4.2.3.2. PA modulation of protein nuclear localization

4.3. PA effect on membrane structures

4.4. PA modulation of lipid trafficking and metabolism

5. Open questions and perspectives

6. Acknowledgment

7. References

\section{Introduction}

Phospholipids are building blocks of cell membranes and also rich sources for generating cellular mediators. Phospholipid content and composition differ among different membranes in a cell and the composition of a membrane also changes during cell development and in response to stress cues. In plants, the most abundant phospholipid phosphatidylcholine (PC) is directly involved in fatty acid modifications and storage lipid synthesis. Phospholipases hydrolyze phospholipids into various products, including phosphatidic acid (PA), diacylglycerol (DAG), free fatty acids (FFAs), and lysophospholipids (LPLs) (Fig. 1), which play important roles in cell regulation and metabolism. Thus, the activities of different phospholipases can have profound impacts on not only membrane integrity, but also cellular metabolism and regulatory processes, such as signal transduction, cytoskeletal dynamics, vesicular trafficking, and secretion. Plant phospholipases are grouped into phospholipase $\mathrm{D}$ (PLD), phospholipase C (PLC), phospholipase $\mathrm{A}_{1}\left(\mathrm{PLA}_{1}\right)$, and PLA $\mathrm{A}_{2}$ based on the site of glycerophospholipid hydrolysis (Fig. 1) [1,2]. Within each type, there are different families or subfamilies of enzymes that differ in structures, substrate selectivities, cofactor requirements, and/or reaction conditions [1-3]. Great progress has been made in recent years toward understanding the various phospholipases [1]. Increasing results indicate that phospholipases play diverse and important roles in plant growth, development, and responses to abiotic and biotic challenges. Here we will review the current understanding of the $\mathrm{D}$ and $\mathrm{C}$ phospholipases that hydrolyze the phosphodiesteric linkage of head groups of phospholipids in plants, highlight some distinctive features unique to plant phospholipases, and discuss some major challenges in the field.

\section{Phospholipase D (PLD)}

PLD hydrolyzes the phosphodiester bond on the head group side of phospholipids to produce soluble head group and PA (Fig. 1). The activity of PLD was first demonstrated in plants [4], and much of the earlier work on PLD concerned its role in membrane lipid catabolism. PLD attracted renewed attention when its role in signal transduction was implicated $[5,6]$. The study of regulatory functions of PLD grew quickly after the PLD gene was first identified and cloned from castor bean [7,8], and then from yeast and human $[9,10]$. Subsequently, multiple PLDs have been characterized in various 
organisms $[11,12]$. All the plant species examined have a PLD family comprising more than 10 PLD genes [13]. The PLD family in the model plant Arabidopsis has been most extensively studied in plants and thereby is described here for the structures, biochemical properties, and cellular functions.

\subsection{Classification and domain structures}

The Arabidopsis PLD family has 12 genes identified, which are designated as $P L D \alpha(1-3), \beta(1,2)$, $\gamma(1-3), \delta, \varepsilon$, and $\zeta(1,2)$, based on the sequence and enzymatic properties (Fig. 2) [14]. $\alpha, \beta, \gamma, \delta$, and $\varepsilon$ type PLDs are C2-PLDs because of the presence of C2 domain near the N-terminus [15]. However, two PLD $\zeta$ s do not have the $\mathrm{C} 2$ domain. Instead, they have pleckstrin homology $(\mathrm{PH})$ and phox homology (PX) domains $[15,16]$.

$\mathrm{C} 2$ domain is involved in binding of $\mathrm{Ca}^{2+}$ and phospholipids, which is required for enzyme activation. C2-PLDs contain a C2 domain consisting of approximately 130 amino acids [14]. PLD $\beta s, \gamma s$ and $\delta$ all possess the key acidic residues for $\mathrm{Ca}^{2+}$ binding while PLDas and PLD $\varepsilon$ lack some of the $\mathrm{Ca}^{2+}$ binding residues [16]. The difference in acidic residues in C2 domain of PLDs may explain different requirement of $\mathrm{Ca}^{2+}$ for enzyme activity (Fig. 2), some of which has been experimentally determined $[16,17]$. PLD $\zeta$ s have PX and PH domains near the N-terminus, which are also present in mammalian PLDs. Both PX and PH domains have different binding affinity for phosphoinositides. In addition, PX domain is able to bind the Src homology 3 (SH3) domain [18-20]. Deletion studies of mammalian PLDs suggest that the PX domain is critical for PLD activity while PH domain is not [21, 22]. Both domains are potential regulatory elements in PLDs, but their exact roles in plant PLD $\zeta_{s}$ need to be determined.

All examined eukaryotic PLDs contain two duplicated catalytic HKD motifs which interact with each other to form the active site [16] (Fig. 2). The HKD motif has the highly conserved HxKxxxD/E sequence $[9,23]$. Point mutagenesis of amino acids in the HKD motif reveals that the HKD residues are critical for PLD activity [24, 25]. These two HKD domains are separated by more than 300 amino acids in 12 Arabidopsis PLDs [16]. In addition to the common ones, individual PLDs have been shown to have different motifs and domains (Fig. 2). PLD $\beta 1$ has a phosphatidylinositol 4,5-bisphosphate $\left[\mathrm{PI}(4,5) \mathrm{P}_{2}\right]$ binding region (PBR1) located after the first HKD domain, and PBR1 binds $\mathrm{PI}(4,5) \mathrm{P}_{2}$ and is essential for PLD $\beta 1$ activity [26]. In addition, $\mathrm{PLD} \beta 1$ is predicted to have two polybasic motifs $(\mathrm{K} / \mathrm{RxxxxK} / \mathrm{RxK} / \mathrm{RK} / \mathrm{R})$ responsible for $\mathrm{PI}(4,5) \mathrm{P}_{2}$ binding flanking the second $\mathrm{HKD}$ domain (Fig. 2), while PLD $\alpha$, $\gamma \mathrm{s}, \delta$ and $\varepsilon$ appear to lack some of the key residues in corresponding region $[16,26]$. PLD $\beta 1$ interacts with actin [27] and an actin binding motif is located after the second HKD motif (Fig. 2) [27]. PLD $\alpha 1$ has a motif between 562 and 586 amino acid residues with high similarity to the DRY motif in proteins interacting with the heterotrimeric $G$ protein subunit $G \alpha$. PLD $\alpha 1$ interacts with $\mathrm{G} \alpha$ and stimulates its GTPase activity [28]. In PLD $\delta$, there is an oleate-binding motif located after the first HKD domain and this motif is responsible for oleate-stimulation of PLD $\delta$ [12] (Fig. 2). The presence of these domains in PLDs provides the basis for differential regulation of PLD functions.

\subsection{Catalytic properties and regulation of PLD activities}

PLDs display distinguishable requirements for $\mathrm{Ca}^{2+}, \mathrm{PI}(4,5) \mathrm{P}_{2}$, oleate, and $\mathrm{pH}$ for optimal enzyme 
activity, and different usage of phospholipid substrates (Fig. 2). The PLD activity assayed in vitro earlier was characterized by its high millimolar need for $\mathrm{Ca}^{2+}$ and strong stimulation by detergents such as SDS. When the gene PLD 1 primarily for the "conventional" PLD activity was suppressed, PLD activities that required much lower, micromolar levels of $\mathrm{Ca}^{2+}$ were discovered [29]. Genes encoding such PLDs, PLD $\beta 1$ and $\gamma$ s were soon identified and later PLD $\zeta 1$ that is $\mathrm{Ca}^{2+}$-independent was identified [11]. The presence and difference in the $\mathrm{C} 2$ domain provide a structural basis for the different $\mathrm{Ca}^{2+}$ dependency [17, 30]. All Arabidopsis C2-PLDs tested, including PLD $\alpha 1, \alpha 3, \beta 1, \gamma 1, \gamma 2$, $\delta$ and $\varepsilon$, require $\mathrm{Ca}^{2+}$ for the enzyme activity [31]. $\mathrm{Ca}^{2+}$ binds to C2-PLDs and enhances the enzyme activity by promoting the lipid substrate to the catalytic site [17, 32]. PLD $\alpha 1, \alpha 3$ and $\varepsilon$ are most active at millimolar $\mathrm{Ca}^{2+}$ whereas PLD $\beta 1, \gamma 1, \gamma 2$, and $\delta$ require micromolar range of $\mathrm{Ca}^{2+}$ for activity. It should be noted that the $\mathrm{Ca}^{2+}$ requirement by $\mathrm{PLD} \alpha 1$ is at near physiological, micromolar range when assayed at acidic $\mathrm{pH}$ 4.5-5.5 in the presence of mixed lipid vesicles [33]. By comparison, PLD $\zeta$ s do not have $\mathrm{C} 2$ domain and have no requirement of $\mathrm{Ca}^{2+}$ (Fig. 2) [31].

$\mathrm{PI}(4,5) \mathrm{P}_{2}$ is another key modulator of most PLDs, and $\mathrm{PI}(4,5) \mathrm{P}_{2}$ binding can enhance substrate affinity of the PLD enzymes [26]. PI(4,5) $\mathrm{P}_{2}$ is required for the activity of PLD $\beta, \gamma$, and $\zeta$. PLD $\alpha$ s and $\varepsilon$ are active without $\mathrm{PI}(4,5) \mathrm{P}_{2}$ which correlates with the fact that some key residues are absent in the $\mathrm{PI}(4,5) \mathrm{P}_{2}$ binding domain [16]. Although $\mathrm{PLD} \delta$ is active without $\mathrm{PI}(4,5) \mathrm{P}_{2}$, addition of $\mathrm{PI}(4,5) \mathrm{P}_{2}$ significantly promotes PLD $\delta$ activity [12]. The activity of PLD $\delta$ is stimulated greatly by the free monounsaturated fatty acid oleate. A region located about 30 amino acids after first HKD domain was identified to be responsible for oleate binding (Fig. 2) [12]. $N$-acylethanolamines (NAEs) which are potentially produced by PLD $\beta$ and PLD $\gamma$ are endogenous inhibitors of PLD $\alpha 1$ [34]. The varied requirements of cofactors indicate that PLDs are regulated and thus activated differentially and may have unique functions in the cell.

C2-PLDs utilize PC, phosphatidylethanolamine (PE), and phosphatidylglycerol (PG) as substrates but with different preferences whereas PX/PH-PLD $\zeta 1$ selectively uses PC as substrate (Fig. 2) [16]. PLD $\alpha 1, \alpha 3$ and $\varepsilon$ prefer PC to PE as substrate whereas PLD $\delta$ and $\gamma 1$ hydrolyze PE at a higher rate than PC. Phosphatidylserine (PS) can be hydrolyzed by PLDs such as PLD $\alpha 3$ and $\varepsilon$ with low activity $[35,36]$. No phosphatidylinositol (PI)-hydrolyzing activity has been detected for the cloned Arabidopsis PLDs when assayed in vitro [31]. The different substrate preferences indicate that individual PLDs may selectively hydrolyze different phospholipids and thus potentially produce PAs with different acyl composition.

Transphosphatidylation is a reaction unique to PLD, in which PLD uses primary alcohol (R-OH) instead of water $(\mathrm{H}-\mathrm{OH})$ to accept phosphatidyl moiety. The formation of phosphatidylalcohol has been used as an indicator of PLD activity and also to suppress PA production by PLD. However, the diversion of PA formation by alcohol is incomplete and alcohols stimulate rather than inhibit PLD activity. Alcohol treatments have been used as a supplemental approach to investigating the function of PLD, but any effect should be interpreted with caution as an alcohol may increase lipid hydrolysis, changes in lipid composition, and/or other cellular effect.

\subsection{Subcellular localization and tissue distribution}


The subcellular localization varies among individual PLDs [31, 37]. PLD $\alpha 1$ is the most abundant PLD which is present in both soluble and membrane fractions. It translocates to membranes to hydrolyze membrane lipids under stress $[38,39]$. PLD $\gamma$ was detected in the plasma membrane, intracellular membrane, nuclei and mitochondria [37]. Detection of PLD $\beta 1$ in different cellular fractions by antibody is not successful which is likely due to low abundance of PLD $\beta 1$ in Arabidopsis tissue [37]. Examination by cellular fraction and confocal imaging indicates that PLD $\zeta 2$ is localized on the tonoplast [40]. PLD $\alpha 3, \delta$ and $\varepsilon$ are primarily associated with the plasma membrane as revealed by immunoblotting, enzyme activity assay or confocal imaging [35, 36, 41]. The exact subcellular localization of other PLDs is yet to be defined.

PLD genes have different expression levels and patterns in Arabidopsis. For example, PLD $\alpha 1, \alpha 3$ and $\varepsilon$ are all expressed in examined organs including inflorescence, flower, silique, stem, leaf and root. However, the expression level of $P L D \alpha 1$ is overall much higher than $P L D \alpha 3$ and $\varepsilon[35,36]$. One exception is that $P L D \alpha 1$ expression is very low in pollen [35]. The expression of $P L D$ genes increases in response to stimuli. $P L D \alpha 1$ and $P L D \delta$ are greatly induced by drought and salt stresses $[42,43]$. $P L D \delta$ mRNA also accumulates under cold stress [44]. $P L D \zeta 2$ expression was increased more than 10 fold under phosphate deprivation [45]. The expression level of $P L D \varepsilon$ is very low and induced by nitrogen starvation [35]. Transcriptional regulation of $P L D$ genes is largely unknown. It was reported that $P L D \zeta 1$ was the direct target of the transcription factor GLABRA2 (GL2). GL2 binds to the promoter of $P L D \zeta 1$ and inhibits its transcription [46].

\subsection{Cellular and physiological functions}

The differences described above in the mode of enzyme activation, expression patterns, and subcellular localization indicate that PLDs can be activated differently and have distinguishable functions. The activity of PLD increases rapidly in response to various environmental stresses. PLDs are involved in plant growth, development, and response to abiotic and biotic stresses. Recent studies that integrate genetic manipulations, phospholipid profiling, and physiological analyses, have made it feasible to delineate the activation of individual PLDs in different physiological processes and in some cases, to determine the role of different PLDs in different steps of the same signaling cascade.

\subsubsection{Distinguishable functions of different PLDs in stress responses}

$P L D \alpha 1$ knockout and its antisense-suppressed plants display alterations in diverse biological processes including water loss [47], reactive oxygen species (ROS) production [47], salt stress [43, 48, 49], abscisic acid (ABA) response, stomatal movement [47, 50, 51], freezing sensitivity, and seed aging [52, 53]. PLD $\delta$ has been reported to be involved in freezing tolerance [44], dehydration [42], $\mathrm{H}_{2} \mathrm{O}_{2}$-induced cell death [54], salt stress [42, 43], ABA response, and drought tolerance [55].

PLD $\alpha 3$ is involved in mediating plant responses to hyperosmotic stresses [35]. PLD $\beta 1$ and $\delta$ are key players in plant resistance to pathogens [56, 57], and the role of different PLDs in plant defense response is described in section 2.4.3. PLD $\varepsilon$ plays an important role in nitrogen signaling, promoting root hair growth and overall biomass production $[36,58]$. PLD $\gamma$ s are shown to be induced by aluminum and knockdown of $P L D \gamma 1$ and $P L D \gamma 2$ confers increased resistance to aluminum stress, indicating that PLD $\gamma$ s negatively regulate plant aluminum tolerance [59]. PLD $\zeta 1$ was found to be a direct target of the homeobox protein GL2, a negative regulator of root hair development [46]. PLDל2 
is involved in phosphate starvation [45, 60], auxin response and vesicle trafficking [61].

\subsubsection{Different PLDs in common physiological processes with different modes of action}

Multiple PLDs have been shown and implicated in the same physiological processes, such as hyperosmotic stress and ABA signaling, but the mechanism of action by different PLDs may differ

(Fig. 3). Knockout of either $P L D \alpha 1$ or $P L D \delta$ results in less response to ABA-induced stomatal closure while loss of both genes renders the stomata almost completely insensitive to ABA-induced closure $[41,50,62,63]$. PLD $\alpha 1$ regulates ABA signaling through its interaction with $\mathrm{G} \alpha$ and through PA inhibition of ABA INSENSITIVE 1 (ABI1) and PA activation of NADPH oxidase to produce ROS (Fig. 3) [47, 50, 51]. The production of $\mathrm{H}_{2} \mathrm{O}_{2}$ oxidizes cytosolic glyceraldehyde-3-phosphate dehydrogenases (GAPCs) and promotes the interaction of oxidized GAPC with PLD $\delta$, leading to activation of PLD $\delta$. PLD $\delta$-derived PA is likely to regulate downstream target in ABA signaling pathway during stomatal closure [64]. Thus, $\mathrm{PLD} \alpha 1$ promotes $\mathrm{H}_{2} \mathrm{O}_{2}$ production, whereas PLD $\delta$ mediates the response to $\mathrm{H}_{2} \mathrm{O}_{2}$ in the ABA signaling pathway (Fig. 3).

Salt stress induces PA production by activating multiple PLDs (e.g. $\alpha 1, \alpha 3$ and $\delta)$ and manipulation of PLDs alters sensitivity to salt stress in Arabidopsis [42, 43, 48, 65, 66]. PLD $\alpha 1$ is induced to produce PA which stimulates mitogen-activated protein kinase 6 (MPK6) to regulate MAPK cascade and regulates microtubule-associated protein 65-1 (MAP65-1) to enhance microtubule polymerization and bundling [48, 65]. Arabidopsis mutant lacking both $P L D \alpha 1$ and $P L D \delta$ exhibits dramatically reduced PA production and enhanced sensitivity under salt stress [43]. Knockout of $P L D \alpha 3$ renders Arabidopsis more sensitive to salt stress while overexpression of $P L D \alpha 3$ enhances the salt tolerance. It is proposed that PLD $\alpha 3$ regulates salt stress response by promoting root growth [36]. However, the exact mechanism of regulation of salt stress response by PLD $\alpha 3$ and PLD $\delta$ remains elusive.

\subsubsection{PLDs involved in plant defense responses}

During pathogen invasion, the plasma membrane-localized pattern recognition receptors (PRRs) of plants recognize conserved microbe-associated molecular pattern (MAMP) molecules that are released by pathogens through secretory systems $[67,68]$. MAMP recognition activates signaling networks that ultimately result in changes in expression of defense-associated genes and immune response [68, 69] (Fig. 4). These MAMP-triggered immunity (MTI) responses render plants resistant to most non-adapted pathogens [67]. On the other hand, intracellular resistance (R) proteins recognize specific pathogen-secreted effectors, such as AvrB, AvrRpm1, and AvrRpt2, resulting in effector-triggered immunity (ETI) [68]. Despite similarities in signaling requirements and defense outputs, ETI induces a stronger response than MTI, as observed in many types of plant defense responses [68-72]. PLD and PA are potentially the early signaling molecules involved in both MTI and ETI in plant cells [73].

\subsubsection{PLDa1 in plant-microbe interactions}

Besides its roles in ABA signaling and abiotic stress responses [14, 38, 50, 51, 62, 74-76], PLD $\alpha 1$ plays a role in plant-microbe interaction and resistance against pathogens [76, 77] (Fig. 4). Rice PLD $\alpha 1$ is recruited to the plasma membrane during pathogen attack [76]. In Arabidopsis, PLD 1 mediates endophytic fungus Piriformospora indica-induced root growth, through an identified PA 
target, 3-PHOSPHOINOSITIDE-DEPENDENT PROTEIN KINASE1 (PDK1) and then Oxidative Signal Inducible1 (OXI1) signaling pathway [77]. PLD $\alpha 1$ may be involved in plant-microbe interactions via $G$ protein-regulated processes. PLD $\alpha 1$ interacts with a $G \alpha$ subunit, most likely in the plasma membrane since PLD $\alpha 1, \mathrm{G} \alpha$, and $\mathrm{G} \beta$ proteins were all translocated to the plasma membrane during ETI responses in a negative mode $[14,69,75,78]$. The heterologous $\mathrm{G}$ protein complexes, $\mathrm{G} \alpha$ and $\mathrm{G} \beta / \mathrm{G} \gamma$, are involved in the plant disease resistance [79-82]. As PLD $\alpha 1$-derived PA targets, NADPH oxidases AtRbohD and AtRbohF, and the PLD $\alpha 1$-targeted G $\alpha-G \beta$ complex, are required for full disease resistance to different $P$ st strains by function in the same pathway [82].

\subsubsection{PLDß1 in plant response to bacterial and fungal pathogens}

The transcript level of $P L D \beta 1$ increased in Arabidopsis, rice, and tomato after challenging with different pathogens or elicitors [54, 83-88]. Suppression of $P L D \beta 1$ expression resulted in increased defense in tomato response to fungal elicitors [83]. Knockdown of $P L D \beta 1$ in rice spontaneously activated the defense responses even in the absence of pathogen infection, such as overproduction of ROS and expression of PATHOGENESIS RELATED (PR) genes [85]. OsPLD $\beta 1$-knockdown rice also exhibited an increased resistance to pathogens including Pyricularia grisea and Xanthomonas oryzae pv. oryzae [85]. In Arabidopsis, $P L D \beta 1$-deficient plants exhibited enhanced resistance to Pseudomonas syringae pv. tomato DC3000 (Pst DC3000) with an increased accumulation of ROS and salicylic acid (SA). On the contrary, PLD $\beta 1$-deficient plants exhibited a decrease in Botrytis cinerea infection-induced jasmonic acid (JA) and PA production, as well as JA-inducible gene expression [56]. PLD $\beta 1$ is responsible for most of the PA production in response to the necrotrophic fungal pathogen $B$. cinerea and virulent Pst DC3000 infection. However, the mechanism by which PLD $\beta 1$ affects PA, SA, JA, and ROS production upon pathogen infection remains to be determined. PLD $\beta 1$ seems to act as a negative regulator of defense responses against biotrophic pathogens, by negatively affecting SA-mediated and positively regulating JA-mediated defense signaling pathways, although there are still undefined points leaving many open questions [56, 58, 82-85, 89-92].

\subsubsection{PLD $\delta$ in defense against non-host penetration fungi}

PLD $\delta$ plays a role in defense against non-host fungal attack (Fig. 4). In endophytic fungus $P$. indica-induced Arabidopsis root growth, PLD $\delta$ mediates the symbiotic interaction and beneficial growth effects, together with PLD $\alpha 1$ [77]. PLD $\delta$ alone was also involved in preventing the non-adapted pathogen barley powdery mildew fungus Blumeria graminis $\mathrm{f}$. $\mathrm{sp}$. hordei and pea powdery mildew fungus Erysiphe pisi from penetration into the Arabidopsis epidermal cell wall [57]. PLD $\delta$ was localized to the plasma membrane at the site of fungal attack, where it surrounds the cell wall reinforcement. PA is required for the resistance against the penetration of powdery mildew fungus, since a decrease in PA production by n-butanol increased the penetration rate of fungal spores on wild-type leaves [57]. Knockout of $P L D \delta$ caused a loss of ETI-induced and cell wall-based defense against the Pst DC3000 (AvrRpm1), suggesting a role of PLD in plant-microbe interaction and defense responses [92].

\subsubsection{Other PLDs potential in plant defense responses}

The expression of $P L D \gamma 1$ increased in response to MTI and ETI pathogen attack [86-88]. Differing from $P L D \beta 1$ and $P L D \alpha 1$ whose transcript levels elevated in response primarily to compactable 
pathogens, the expression of $P L D \gamma 1$ and a lysophospholipase gene were also up-regulated during gene-gene interactions, leading to the hypersensitive response (HR) [88]. PLD $\gamma 1$ was relocated to the plasma membrane during ETI responses; however, the effect of PLD $\gamma 1$ on the defense response is unclear [69]. Recently, it was found that the PA produced by PLD $\zeta$ or other PLDs interacts with a protein phosphatase type 2A subunit A1 (PP2A) and modulates PP2A activity [93] (Fig. 5). A potential PP2A holoenzyme inhibits immune responses triggered by several MAMPs and anti-bacterial immunity, and PP2A is constitutively associated with BAK1 in planta and modifies flagellin sensing (FLS)-BAK1 phosphorylation status [94]. PA also binds to BZR1 directly and decreases BZR1 dephosphorylation, which is involved in plant defense responses [95] (Fig. 5). However, modification of immune responses by PLD $\zeta$ s directly or indirectly needs to be further tested.

\subsubsection{PLD involvement in plant-virus interactions}

In tobacco response to tobacco mosaic virus (TMV) infection, PLD activity and PA contents increased after the appearance of necrotic lesions and their subsequent expansion [96]. During the replication of a plant positive-strand RNA [+RNA] virus, red clover necrotic mosaic virus (RCNMV) in Nicotiana benthamiana, NbPLD $\alpha$ and NbPLD $\beta$ were found in the membrane-bound replicase complexes that contain multiple viral and host components [97]. Gene-silencing and pharmacological inhibition experiments indicated that these PLDs and their derived PA are required for viral RNA replication. Knockdown of $N b P L D \alpha$ and $N b P L D \beta$ or PLD inhibitor treatments repressed the viral replication of RCNMV RNA, but exogenous application of PA enhanced viral RNA replication in plant cells and plant-derived cell-free extracts. The transcripts of both PLD $\alpha$ and $P L D \beta$ increased and the amount of PAs increased upon infection by RCNMV. PA can bind to a viral replication protein p27 and enhance the viral replication by upregulating the activity/assembly of the viral replicase complexes in vitro to facilitate the replication [97]. RCNMV alters cellular lipid metabolism to establish a suitable environment for viral replication indicating that RCNMV hijacks host PA-producing enzymes for replication of their own lives.

\subsection{Mechanisms of PLD effects on cellular functions}

The modes of PLD actions that affect plant growth, development and stress tolerance are multifaceted. These involve PLD production of PA as lipid mediators, PLD direct interaction with effector proteins, regulation of cytoskeletal dynamics and vesicular trafficking, lipid/membrane remodeling, and membrane degradation.

\subsubsection{Production of the lipid mediator phosphatidic acid (PA)}

One key mechanism of PLD functions in plants is through production of signaling messenger PA (Figs. 1,3,4) [14]. PLD-mediated PA production has been demonstrated under different conditions, such as ABA treatment, wounding, drought, and freezing. The use of PLD mutants enables identification of different PLDs involved in the PA production under specific conditions. In some cases, the protein targets of PA have been identified. PA is emerging as an important lipid regulator involved in different physiological functions in plants, and the function of PA is described in Section 4 below. 


\subsubsection{PLD interaction with proteins}

PLDs have been shown to interact with different proteins, including protease inhibitors, Ga, GAPC, actin, and tubulin. These interactions have reciprocal effects on PLDs and their effector proteins. They regulate PLD activity and intracellular locations and also affect cellular functions through interaction with other effector proteins to mediate cell signaling in various biological processes. For example, PLD $\alpha 1$ interacts with the G $\alpha$ protein through its DRY motif to mediate ABA signaling in Arabidopsis $[28,51]$. The interaction of PLD $\alpha 1-G \alpha$ modulates reciprocally the activities of PLD $\alpha 1$ and G $\alpha$. Specifically, incubation of G $\alpha$ with PLD $\alpha 1$ inhibits the activity of PLD $\alpha 1$. Addition of GTP inhibits PLD $\alpha 1-G \alpha$ interaction and relieves the inhibition effect of G $\alpha$ on PLD $\alpha 1$. Meanwhile, GTPase activity of $\mathrm{G} \alpha$ is increased when PLD $\alpha 1$ is present during the assay [28]. In plants, PLD $\alpha 1-G \alpha$ interaction is disrupted by ABA which leads to activation of PLD $\alpha 1$ [51]. Two GAPCs are identified to be associated with PLD $\delta$ under oxidative stress. Oxidative stress promotes the PLD $\delta$-GAPC interaction, which increases the activity of PLD $\delta$. PLD $\delta$-GAPC interaction is found to mediate ABA-induced stomatal closure. Plants are less responsive to drought stress and lose more water when $P L D \delta$ or GAPCs are knocked out [41]. Furthermore, two recent reports describe that PA, the product of PLD and a key intermediate in glycerolipid biosynthesis, interacts with GAPC [98, 99]. The PLD $\delta$-GAPC and PA-GAPC interactions may provide connections between lipid signaling and primary metabolism which requires further investigation (Fig. 3). PLD and PA also interact with cytoskeletal proteins, such as actins and microtubules $[52,53,65,100]$, which is discussed in detail in section 2.5.3.

\subsubsection{PLD regulation of actin/microtubule cytoskeletons}

\subsubsection{PLDß1 interacts with actin cytoskeleton}

The interaction between PLD and actin is evolutionarily conserved between mammalian and plant cells [27, 101]. Mammalian PLD binds both G-actin and F-actin filaments whereas monomeric G-actin inhibits PLD1 activity but polymerized F-actin augments PLD1 activity [27, 102, 103]. Likewise, PLD $\beta 1$ binds to human actin and its activity is enhanced by F-actin and inhibited by G-actin [104]. Similarly, F-actin stimulated but G-actin inhibited tobacco NtPLD $\beta 1$ activity; NtPLD $\beta 1$ and actin interaction in tobacco has function in pollen tube growth [52].

\subsubsection{PLD $\delta$ interacts with microtubules}

PLD $\delta$ has been identified as a cortical microtubule-binding protein $[53,100,105]$. Both actin 7 and $\beta$-tubulin were cosedimented with GFP-PLD $\delta$ in a pull-down assay from transgenic Arabidopsis suspension cells $[106,107]$. These studies suggest that PLD $\delta$ activation is critical to trigger microtubule reorganization. The capability of PLD $\delta$ and its product PA to regulate microtubule cytoskeletal dynamics might contribute to the penetration resistance against non-host powdery mildew fungi, and PLD $\delta$ is translocated to the attack site [55]. It is likely that other PLDs are also involved in microtubule reorganization since knockout of $P L D \delta$ did not render mutant plants grow and develop abnormally [89].

\subsubsection{Interactions of other PLDs with cytoskeletons}

PLD-derived PA mediates the PLD $\alpha 1$-induced salt stress and wounding responses, by modulating microtubule cytoskeleton and protein kinase signaling cascade [38, 48, 50, 108, 109]. PLD $\alpha 1$-derived 
PA targets both MAPK and MAP65-1 to regulate microtubule polymerization and bundling under salt stress $[48,66]$. PLD $\zeta 1$ and PLD $\zeta 1$-derived PA are also involved in actin cytoskeleton dynamics [45]. Overexpression of PLD $\zeta 1$ results in destructive actin cytoskeleton dynamics through the action of PA, since PA generation inhibitor blocked the effect [45]. Thus, it seems that most PLDs have capacity to directly or indirectly, such as via PA, to influence actin/tubulin cytoskeletons. PLD-PAs may mediate the formation of membrane lipid-cytoskeleton interfaces to coordinately regulate subcellular dynamics.

\subsubsection{PLD regulation of vesicular trafficking}

PLD and PA in mammalian systems affect vesicle trafficking-related processes involved in exocytosis, endocytosis, membrane fusion, and vesicle budding [101, 110-112]. Small GTPases, such as ADP-ribosylation factor (ARF) GTPases in the Golgi complex, ARF and Rho GTPase-binding proteins and soluble $N$-ethylmaleimide-sensitive factor attachment protein receptors (SNAREs), are vesicle coat proteins, which facilitate membrane trafficking and fusion [113]. Meanwhile, they are also activators of PLD for generating PA to recruit other proteins to membranes or to facilitate vesicle formation, vesicle trafficking, or fusion with the target organelle (Fig. 6) [110-112]. The yeast SNARE protein Spo20p binds to PA [114]. In plants, an Arabidopsis ARF GTPase-activating protein 7 (AGD7) regulates AtARF1 in the Golgi complex, which is involved in vesicle trafficking and fusion, in a PA-dependent manner (Fig. 6) [115]. The negatively charged and cone-shaped PAs generated by PLDs on a membrane can affect vesicle formation and membrane fission and fusion, which will be discussed in section 4.3 (Fig. 6) [110-113, 116-119].

n-Butanol treatment arrested vesicle secretion and complete fragmentation of Golgi membranes and disorganized networks of microtubules and actin, inhibiting plant growth and development $[100,106$, $120,121]$. In tobacco cells, n-butanol treatment resulted in extended curved cisternaes in BY-2 Golgi apparatus, but endoplasmic reticulum (ER)-Golgi fusion hybrids could not be observed [122]. Furthermore, n-butanol elicited a reversible release of the GTPase ARF1 from Golgi membranes [122]. Coatomer (COPI)-vesicles formation requires PLD-PA and the sequential recruitment of ARF1 since COPI proteins prefer to bind to membranes enriched in the PA and PIP ${ }_{2}$. Therefore, a feedback loop between PIP 2 , PLD-PA, and coat proteins, such as ARF1, are critical for membrane vesicle formation and trafficking (Fig. 6). PA is not only required for COPI-vesicle formation, but also for later events in the secretory pathway, in particular, vesicle release at the trans-Golgi $[122,123]$. Therefore, inhibiting the formation of PA with n-butanol blocked coatomer recruitment and COPI-vesicle formation and stopped the secretory pathway. The vesicle trafficking is critically dependent of cytoskeleton dynamics. In addition, membrane PI phosphates (PIPs) and their inter-conversion by various kinases and phosphatases also mediate the interactions of PLD-PA with cytoskeleton and vesicle trafficking $[116,122]$. PI $(4,5) \mathrm{P}_{2}$ activates PLD whereas PA binds to and stimulates PI(4)P-5 kinase that synthesize $\mathrm{PIP}_{2}$ [122-124]. PIP 2 has critical functions in cytoskeletal reorganization and membrane trafficking (Fig. 6). Thus, some of the PLD and PA effects on actin dynamics could result from their effects on $\mathrm{PIP}_{2}$ production. Arabidopsis heterodimeric capping protein $(\mathrm{AtCP})$ is bound and regulated by both PA and $\mathrm{PIP}_{2}[116,124] . \mathrm{PIP}_{2}$ levels control the adhesion of the membrane bilayers to the underlying cytoskeleton. Elevated $\mathrm{PIP}_{2}$ levels affect the cortical plasma membrane-cytoskeleton structure $[125,126]$ and regulate numerous actin-binding 
proteins [127-133].

\subsubsection{Lipid remodeling and changing membrane lipid composition}

Membrane lipid composition undergoes dynamic changes and is important for plant's adaptation to the environment. Phospholipids were decreased and galactolipids were increased when phosphorus was limited in plants [45]. Loss of both $P L D \zeta s$ resulted in a decrease of PC and increase in digalactosyldiacylglycerol (DGDG) under phosphorus limited condition. Lipid profiling results suggest that PLDs are hydrolyzing PC to supply phosphorus for cell metabolism and DAG for galactolipid synthesis during phosphorus starvation [45]. This study indicates that PLDלs are positive regulator of plant adaptation to phosphorus deficiency.

\subsubsection{Lipid degradation and membrane deterioration under severe stress}

PLD is one class of the major lipases that mediate hydrolysis of phospholipid during membrane degradation [31]. Numerous studies implicate that PLDs are activated to hydrolyze phospholipids during stress responses or nutrition deprivations. For example, under freezing treatment, a large decrease in major phospholipids, such as PC, PE and PG was observed, but PA, lysophosphatidylcholine (LPC) and lysophosphatidylethanolamine (LPE) increased. These changes indicate that phospholipases are activated by freezing. The PA level is increased more than 5 fold at $-8^{\circ} \mathrm{C}$, indicating that PLD activity is dramatically increased [130]. Indeed, suppression of PLD 1 led to less decrease of PC and lower level of PA under freezing stress, indicating important roles of PLD in maintaining membrane integrity and possibly providing lipid messengers under freezing stress [134]. Knockdown of $P L D \alpha 1$ enhanced seed resistance to aging and oil stability in Arabidopsis and soybean, resulting from the catabolic effect of the PLD and thus improved membrane integrity [135, $136]$.

\section{Phospholipase C (PLC)}

PLC hydrolyzes the phosphodiester bond on the glycerol side of phospholipids to produce DAG and a phosphorylated head group (Fig. 1). PLCs in plants can be divided into three groups according to substrate specificity and cellular functions: non-specific PLC (NPC) that acts on the common phospholipids, such as PC and PE, phosphoinositide-specific PLC (PI-PLC) that hydrolyzes phosphoinositides, and the glycosylphosphatidylinositol (GPI)-PLC that hydrolyzes GPI-anchored proteins [2]. Here we describe the progress made on the intracellular NPC and PI-PLC (Fig. 7).

\subsection{Non-specific phospholipase C (NPC) hydrolyzing common membrane phospholipids}

The activity of PC-hydrolyzing PLC was reported some time ago in membrane and soluble fractions of various plant species and tissues [137-139]. However, the analysis of PC-PLC function in plants was hindered by the lack of molecular information. A sequence similarity search against the gram-negative bacterial PC-PLC identified six PC-PLC in Arabidopsis genome [2]. Later the six genes in Arabidopsis were named AtNPC1 to AtNPC6 [140], hereafter dessignated as NPC1 to NPC6. Recent analyses of several members of the NPC family show that NPCs play important roles in various physiological processes, and this also provides insights into the signaling role of DAG in plants that has long remained questionable. 


\subsubsection{Classification and domain structures}

The Arabidopsis NPC proteins are approximately $60 \mathrm{kDa}$ and consist of 514 538 amino acid residues [140]. Amino acid sequences among the six NPCs vary with an exceptionally high identity of $84.7 \%$ between NPC4 and NPC5. Additionally, five NPC orthologues were recently identified in rice [141], three in Proteaceae (Hakea prostrata) [142], and a phylogenetic analysis revealed some NPC families in evolutionarily distinct plant species [143]. NPCs possess a phosphoesterase domain necessary for esterase activity and three unknown domains highly conserved with a bacterial (Mycobacterium tuberculosis) PC-PLC. No membrane-spanning region was identified but predicted signal peptides were present in NPC1, NPC2 and NPC6 [140]. Homology modeling of Arabidopsis NPC2 based on the crystal structure of a bacterial acid phosphatase (AcpA in Francisella tularensis) suggests that the NPC backbone consists of a $\beta$-sheet surrounded by seven $\alpha$-helixes [143]. Most of the active site residues are conserved between NPC and the AcpA, suggesting a common catalytic reaction mechanism among plant NPCs, bacterial PC-PLCs, and homologous acid phosphatases. Sequence analysis identified a C-terminal domain that was the most divergent part of NPC sequences thus believed to be responsible for the functional diversity of NPCs [143].

\subsubsection{Substrate preference and regulation of NPC activities}

Recombinant NPC4 expressed in E. coli was able to hydrolyze PC and PE with great efficiency and PG, PS, PA, and PI $(4,5) \mathrm{P}_{2}$ to a smaller extent $[140,144]$. Although acyl chain preference of NPC4 was not directly measured, mass spectrometry-based DAG profiling enabled inference of in vivo acyl chain specificity. Among 27 DAG molecular species identified by ESI-MS/MS, levels of DAG species with 18:2/16:0, 18:3/16:0, 18:3/18:2, and 18:3/18:3 were decreased in NPC4 T-DNA knockout mutant (npc4) compared to wild-type [144], indicative of NPC4 activity biased for the substrates with these acyl chain compositions. NPC5 hydrolyzes PC and PE, but its activity in vitro is approximately 40 times less than that of NPC4. The knockout mutant npc5 showed a decrease in most of 31 DAG molecular species identified [145], implying its broader acyl chain preference than NPC4. Interestingly, recombinant NPC3 displayed phosphatase activity for lysophosphatidic acid (LPA) to produce monoacylglycerol with a negligible activity for other phospholipids including other LPLs [146]. All LPA molecular species tested were efficiently hydrolyzed by NPC3 in vitro with 18:0 LPA slightly less efficient. No enzyme activity has been reported so far for NPC1, NPC2, and NPC6. NPC activity has been described in other plant species as well as in Arabidopsis. DAG derived from fluorescently labeled or radio-labeled PC was detected in cultured parsley and tobacco cells and in petunia (Petunia hybrid) extracts [147, 148].

Specific effectors of NPC activity may provide pharmacological tools for functional characterization of the enzyme. Unlike many phospholipases that are dependent on $\mathrm{Ca}^{2+}$, NPC4 activity is independent of $\mathrm{Ca}^{2}$, and slightly increased by the addition of EGTA, presumably due to the chelation of inhibitory divalent cations such as $\mathrm{Co}^{2+}, \mathrm{Mn}^{2+}$, or $\mathrm{Zn}^{2+}$ [140]. The LPA phosphatase activity of NPC3 was reduced by some detergents, such as Triton X-100, NP-40 and CHAPS, in a dose-dependent manner. NPC3 activity was also inhibited by certain LPLs, including LPC and LPE, presumably through competitive inhibition of the structurally similar compounds [146]. NPC3 was unresponsive to $\mathrm{Mg}^{2+}$, $\mathrm{Ca}^{2+}$, and $\mathrm{Mn}^{2+}$. NPC activity in tobacco BY-2 cells was decreased with aluminum treatment both in vivo and in vitro in dose- and time-dependent manners, and the aluminum inhibition was also 
observed in tobacco pollen tube [149]. Aluminum also reduced PC-derived DAG production in Arabidopsis and this was rescued by NPC4 overexpression and $n p c 4$ was more sensitive to aluminum stress [150]. The aluminum-decreased NPC activity in Arabidopsis was later found to be through aluminum-induced changes in plasma membrane physical properties [151]. NPC activity was down-regulated in parsley cells by a glycoprotein elicitor from Phytophthra sojae and in tobacco cells by the small protein cryptogein from Phytophthra cryptogea [147]. A brassinosteroid hormone 24-epibrassinolide (24-EBR) and salt both increased NPC activity in Brassica napus, with concomitant increase in PLD activity [152]. It remains unclear whether the reduction of NPC activity was by the suppression of $N P C$ expression or by the inhibition of its catalytic activity.

\subsubsection{Expression patterns and subcellular localization}

Arabidopsis NPCs are expressed in relatively low abundance with the highest expression level of $N P C 6$ and the lowest for NPC4 and NPC5 in most tissues [144, 153]. Quantitative analysis from 6-week old Arabidopsis demonstrated that $N P C 1, N P C 2$ and $N P C 6$ are expressed predominantly in siliques, $N P C 3$ in roots, $N P C 4$ in mature leaves, and $N P C 5$ in inflorescences $[144,145,153]$. Histochemical studies using $\beta$-glucuronidase (GUS) revealed a similar expression pattern between $N P C 3$ and NPC4 throughout all developmental stages, with strong expression in root tips and pollen sac tissues and around margins of leaves [153]. High expression of NPC6 in pistils was recently demonstrated by quantitative analysis using Arabidopsis homeotic mutants whose flowers were enriched with specific floral organs [154]. In rice, OSNPC1 and OSNPC3 were expressed in the highest and lowest levels, respectively, in all tissues examined. All OsNPCs, except for OsNPC3, were highly expressed in reproductive tissues (panicles and seeds) in comparison with vegetative tissues (leaves, roots, and seedlings) [141].

The transcript level of NPCS changes in response to nutritional availability, hormones, stresses, and organ development. The expression of NPC4 and NPC5 was induced in Arabidopsis under phosphorus deprivation $[140,153,155]$. This induction has been implicated in membrane remodeling under phosphorus-deficient conditions, together with involvement of PLD as described in section 2.5.5, which will be discussed in detail in section 3.1.4.1. Phosphorus starvation also induced protein expression of a putative NPC4-like phosphoesterase in oat [156]. NPC3 and NPC4 were induced by auxin and brassinolide (BL), and NPC4 also responded to cytokinin [153], ABA [144], and aluminum [150]. Transcriptomic analysis revealed that $N P C 6$ was up-regulated by ABA and slightly down-regulated by zeatin [157]. Meanwhile, NPC5 expression showed a marked increase as flowers develop and this was coincident with a decrease in some phospholipids and an increase in galactolipids during the flower development $[153,158]$. Salt stress was shown to induce the expression of NPC4 and NPC5, of which NPC4 expression was more significantly increased [145, 159]. Most of rice NPCs, except for $O S N P C 5$, were slightly induced by both salt and drought stress [141].

Subcellular localization of Arabidopsis NPC proteins have been specifically identified for NPC4 and NPC5. NPC4 is associated with the plasma membrane whereas NPC5 is predominantly localized in the cytosol $[140,145,155]$. NPC3 was found in the tonoplast following mass spectrometry-based protein identification of vacuole proteome in Arabidopsis [160]. No direct evidence has been reported 
for the distribution of the other Arabidopsis NPCs at subcellular level. Intracellular location of other plant NPCs has been studied for tobacco and oat by NPC activity assay and immunodetection, respectively. NPC activity was highest in the fraction enriched with the plasma membrane in tobacco BY-2 cells, followed by microsomal fraction, but barely detected in cytosolic fraction [149]. The plasma membrane association of NPC was also found in oat roots using Arabidopsis NPC4-specific antibody [156]. Confocal microscopic analyses demonstrated that OsNPC1 and OsNPC3 were localized in the cytoplasm and the chloroplast/plastids, respectively [141]. Considering the hydrophobic nature of NPC substrates, the cytosolic NPCs are believed to relocate to the membranes for physical contact with their substrates upon stimulation.

\subsubsection{Cellular and physiological functions}

\subsubsection{Lipid remodeling and plant response to phosphate deprivation}

As noted earlier, under phosphorus-limited condition substitution of membrane phospholipids by the non-phosphorus galactolipid DGDG is a key process to mobilize inorganic phosphate (Pi) from phospholipids and at the same time to maintain membrane integrity in plant cells [161, 162]. The NPC activity produces DAG, potentially as a key precursor for DGDG synthesis. The expression of NPC4 is greatly induced upon Pi starvation, but knockout of NPC4 did not change the contents of PC and DGDG under Pi deprivation [140]. So the exact role of NPC4 in lipid remodeling under Pi deprivation remains unknown. On the other hand, knockout of NPC5 resulted in a significant decrease in DGDG levels in leaves during Pi starvation [155]. It has been suggested that NPC5 is involved in Pi deficit-induced DGDG accumulation in leaves. Endogenous levels of DAG were decreased in $n p c 5$ $(\sim 42 \%)$ and $n p c 4(\sim 19 \%)[144,145]$, indicating that NPC5 is the major contributor to DAG formation, thus DGDG synthesis in plants, despite its much lower in vitro activity than NPC4 (see section 3.1.2). Both NPC4 and NPC5 are believed to be regulated, in part, by a MYB family transcription factor phosphate starvation response 1 (PHR1), as demonstrated by the presence of PHR1-binding P1BS element in the $N P C$ promoters and their expression reduced in phrl under Pi starvation [163]. NPC5 is responsible for only $\sim 50 \%$ of DGDG produced by Pi deprivation in leaves [155]. NPC3 was found to be involved in Pi-dependent lateral root development in Arabidopsis. NPC3 knockout mutants exhibited significantly lower lateral root densities upon Pi deprivation than wild-type [153]. This was proposed due to auxin signaling impaired by NPC3 mutation as auxin is involved in $\mathrm{Pi}$ deficiency-triggered promotion of lateral root development [164].

\subsubsection{Osmotic, salt, and heat stress}

High salinity and water deficit caused by environmental changes, particularly drought, are major factors to cause hyperosmotic stress in plants, eventually limiting plant growth and productivity. It was found that $n p c 4$ was more sensitive to salt stress than wild-type, producing fewer viable non-bleached seedlings when grown with $200 \mathrm{mM} \mathrm{NaCl}$ [144]. Conversely, seedlings of two independent transgenic lines overexpressing NPC4 were significantly more viable than wild-type under the salt-stressed condition [144]. The effect of NPC4 manipulation on stress-responsive seedling growth was also observed under water-deficient conditions [144], suggesting that NPC4 is possibly involved in the process to cope with hyperosmotic stress. Another study revealed that NPC4 expression was localized in root tips and highly induced by salt treatment, leading to salt-induced DAG accumulation [159]. NPC4 knockout plants displayed increased sensitivity to salt stress in root 
elongation, seedling biomass, and seed germination [159]. NPC5 mediates Arabidopsis response to salt stress, particularly in lateral root development. NPC 5 expression was greatly induced by salt treatment $[145,159]$. NPC5 knockout Arabidopsis exhibited a reduced number of lateral roots under salt-stressed condition and the opposite effect was observed when NPC5 was overexpressed. Interestingly, the lateral root response of $n p c 5$ to salt was most significant at $75 \mathrm{mM} \mathrm{NaCl}$ [145], suggesting that different NPCs may function under differential intensities of salt stress: NPC4 at high salt levels and NPC5 at mild salt stress conditions.

Arabidopsis NPC1 was recently shown to hydrolyze PC into DAG in vitro and NPC1-GFP fusion was localized in secretory pathway compartments in Arabidopsis roots [164]. NPC activity was increased in response of tobacco BY-2 cells to heat stress and genetic manipulation $(\mathrm{KO} / \mathrm{OE})$ demonstrated the implication of NPC1 in heat tolerance in Arabidopsis [164]..

\subsubsection{Hormone responses}

Both drought and high salinity are known to induce ABA production, leading to the induction of stress response genes [165]. The increased salt sensitivity of $n p c 4$ could be attributed to ABA signaling impaired by NPC4 disruption as the salt-stressed mutants displayed reduced expression of certain ABA-responsive genes, compared to wild-type [144, 159]. Indeed, npc4 displayed reduced ABA sensitivity and $N P C 4$ overexpressors were hypersensitive to ABA, compared to wild-type, in seed germination, root elongation, and stomatal movement [144]. On the other hand, NPC5 appeared to be associated with auxin signaling, as evidenced by reduced sensitivity of $n p c 5$ to auxin-mediated root growth [145]. In this regard, it should be noted that the reduced number of lateral roots of $n p c 5$ under salt-stressed conditions was not observed when subjected to osmotic stresses from sorbitol or mannitol treatment [145]. Thus, it would be possible that NPC4 mediates hyperosmotic stress response via ABA signaling whereas NPC5 is involved in salt-specific response through auxin signaling. NPC has also been reported to play a role in BL responses. GUS expression driven by either NPC3 or NPC4 promoter was increased in BL-treated Arabidopsis [153]. Npc3 and $n p c 4$ showed BL sensitivity altered within certain ranges of BL concentrations in primary root length and lateral root density. Implication of NPC in BL signaling is also supported by the recent report of NPC activity increased by 23-EBR in B. napus [152].

\subsubsection{Mechanisms of NPC actions: DAG functions}

The direct lipid product of NPC is DAG and the study of the regulatory function of DAG has been challenging in plants due to the diverse nature of DAG metabolic pathways (Fig. 7). DAG can be generated both anabolically from an intermediate of glycolysis through a biosynthetic pathway known as the Kennedy pathway [8] and through lipase-catalyzed breakdown of membrane lipids. Three major routes are known for the lipase-mediated DAG production: direct cleavage of membrane phospholipids by NPC and PI-PLC and dephosphorylation of PLD-produced PA by the action of PA phosphatase (PAP) or lipid phosphate phosphatase (LPP) (Fig. 7) [148, 166]. NPC can function as a provider of DAG backbone for the biosynthesis of diverse glycerolipid species, including phospholipids, glycolipids, sulpholipids, and storage triacylglycerols (TAGs) [143]. Although the degree to which NPC contributes to the formation of total cellular DAG remains unclear, as noted, genetic manipulation of $N P C$ resulted in altered levels of DAG under normal growth and 
nutrition-limited/stressed conditions. This suggests that NPC is likely involved both in normal plant growth/development by supplying DAG backbone for the biosynthesis of diverse glycerolipid species and in stress-triggered signal transduction by providing DAG as a lipid second messenger. The role of DAG as a second messenger has remained as an open question in plants because plants lack some of the well documented DAG protein targets, like protein kinase $\mathrm{C}(\mathrm{PKC})$ as in animals, and DAG is rapidly phosphorylated to the signaling molecule PA by DAG kinase (DGK) [143, 167]. However, a number of earlier pharmacological studies described that phorbol esters, PA-unrelated DAG analogues, promoted cellular and physiological responses in diverse plant species [168-172]. In addition, environmental stresses can induce the expression of genes encoding enzymes to convert PA to DAG, such as LPP or PAP, signifying roles of DAG in stress responses [173, 174].

Recent studies combining genetic manipulation, pharmacological treatments, and physiological analyses have provided direct evidence for the bioactivity of DAG originated by NPC [144, 145]. The reduced number of lateral roots in $n p c 5$ treated with salt was fully restored to wild-type level by the addition of exogenous DAG, but the restoration was marginal when treated with the same amount of PA [145]. This suggests that DAG, but not PA, plays an essential role in the regulation of lateral root development under salt stress. Another study reported that tobacco BY-2 cells treated with aluminum showed a decrease in NPC activity and significant reduction of DAG content [149]. In the presence of aluminum, tobacco pollen tubes showed retarded growth and their DAG content was also significantly reduced [149]. Recently this was found to be partially rescued by overexpression of Arabidopsis NPC4 [150]. The application of exogenous DAG, but not PA, could recover this growth restriction nearly to the level untreated with aluminum [149], suggesting that DAG produced by NPC is involved in cellular response to aluminum toxicity.

Under well-watered control conditions, $n p c 4$ plants had a smaller stomatal aperture and lower transpiration rates than the wild-type, and addition of DAG restored the stomatal phenotype in npc4 [144]. The results suggest that NPC4-produced DAG is involved in promoting stomatal opening under well-watered conditions (Fig. 7). An earlier study using Vicia faba and synthetic DAG indicated that DAG promoted stomatal opening by activating an ion pump in the guard cell plasma membrane and inhibited stomatal closure by possibly inhibiting $\mathrm{K}^{+}$efflux [175]. Under water deficits, on the other hand, $n p c 4$ plants tended to lose more water and had lower water use efficiency than wild-type. It has been proposed that under well-watered conditions, NPC4 and its derived DAG are involved in promoting stomatal opening. Under stress, however, DAG produced by NPC4 is converted to PA, and the NPC4/DGK pathway promotes root and plant growth in response to ABA and water deficit [144]. The establishment and elucidation of DAG as a class of signaling lipids in plants will be helped greatly by the identification of its downstream protein targets. Plant proteomes contain protein domains with similarity to the $\mathrm{C} 1$ domain, a small cysteine-rich DAG-binding domain in animals. In addition, many other proteins, other than canonical PKCs, have been found to interact with DAG in animal cells. Identification of such DAG-binding proteins and downstream effectors along DAG signaling pathways in plants will uncover cellular functions of NPC and further, unidentified roles of the plant PLC family.

\subsection{PI-PLC: Phosphoinositide-specific PLCs}


PI-PLC hydrolyzes PI(4,5) $\mathrm{P}_{2}$ to generate DAG and inositol 1,4,5-trisphosphate $\left(\mathrm{IP}_{3}\right.$; Fig. 8) [3, 176]. PI-PLC is widely distributed in various organisms from bacteria, yeast, plants to mammals. Increasing studies indicate that PI-PLCs play important roles in plant growth, development and stress response. However, whereas the signaling function of PI-PLCs has been well documented in animal systems, the mechanism of action of PI-PLC in plants remains to be elucidated.

\subsubsection{Classification and domain structures}

Both animal and plant genomes contain multiple genes encoding PI-PLC. Mammalian PI-PLC consists of 13 members, which are divided into six isoforms including PI-PLC $\beta, \gamma, \delta, \varepsilon, \eta$, and $\zeta$ based on the domain structure, sequence similarity, and biochemical properties [177-179]. Multiple PI-PLCs have been reported in different plants species, including Arabidopsis [180, 181], rice [141], wheat [182, 183], tomato [184], soybean [185, 186], potato [187], pea [188], B. napus [189], mung bean [190], oat [191], lily [192], maize [193], and physcomitrella (Physcomitrella patens) [194, 195], and their structures resemble animal PI-PLC $\zeta$. Arabidopsis contains nine PI-PLCs, AtPLC1-AtPLC9 [180]. Based on the sequence alignment and phylogenetic comparison, Arabidopsis and rice PI-PLC genes were likely derived from the single origin through duplications $[141,196]$. The gene pairs of AtPLC4 /AtPLC5 and AtPLC8 / AtPLC9 were probably duplicated in a tandem manner [196].

Plant PI-PLCs have multiple conserved structural folds, including catalytic $\mathrm{X}$ and $\mathrm{Y}$ domains that form a TIM barrel-like structure essential for its phosphoesterase activity, and $\mathrm{Ca}^{2+}$ /phospholipid-binding $\mathrm{C} 2$ domain at the C-terminus (Fig. 8). The $\mathrm{N}$-terminal sequence is less conserved among the plant species $[179,190,197,198]$. In animals, EF-hand domain acts as a regulatory domain that binds $\mathrm{Ca}^{2+}$ and lipids [199]. Most plant PI-PLCs possess an EF-hand lobe that may be involved in membrane binding in N-terminus (Fig. 8). Mammalian PI-PLC $\zeta$ binds PI $(4,5) \mathrm{P}_{2}$ via the $\mathrm{XY}$ linker [200]. The $\mathrm{Ca}^{2+}$ binding by a $\mathrm{C} 2$ domain results in hydrophobicity changes, which is responsible for its membrane targeting [201]. The $\mathrm{C} 2$ domain alone of a rice PI-PLC is capable of targeting the enzyme to the membrane in response to $\mathrm{Ca}^{2+}$ [201]. The membrane targeting may also be mediated by other effectors. Tobacco PI-PLC targeting to the plasma membrane is mediated by the interaction between the $\mathrm{C} 2$ domain and $\mathrm{NtC} 7$, a transmembrane protein [202]. EF-hand of plant PI-PLC is also responsible for the enzyme targeting to membranes to facilitate its affinity to substrates. The N-terminal EF-hand of AtPLC2 is important for PI-PLC catalytic activity [203].

\subsubsection{Catalytic properties and regulation}

The activity of PI-PLC depends on $\mathrm{Ca}^{2+}$ that regulates not only catalytic activity but also subcellular localization and substrate preference of the enzyme. In vitro assays demonstrated that PI-PLC uses $\mathrm{PI}(4,5) \mathrm{P}_{2}, \mathrm{PI}(4) \mathrm{P}$, or PI as substrates, depending on $\mathrm{Ca}^{2+}$ concentrations. PI-PLC does not use phosphorylated D3 PI derivatives, such as $\mathrm{PI}(3) \mathrm{P}, \mathrm{PI}(3,4) \mathrm{P}_{2}, \mathrm{PI}(3,5) \mathrm{P}_{2}, \mathrm{PI}(3,4,5) \mathrm{P}_{3}$ as substrates [200]. Plant PI-PLC is found in both soluble and membrane-associated forms: soluble PI-PLC generally prefers $\mathrm{PI}$ to $\mathrm{PI}(4,5) \mathrm{P}_{2}$ and $\mathrm{PI}(4) \mathrm{P}$ under millimolar levels of $\mathrm{Ca}^{2+}$, whereas membrane-associated PI-PLC selects PI(4,5) $\mathrm{P}_{2}$ and PI(4)P as substrates under micromolar $\mathrm{Ca}^{2+}[204,205]$. Different PI-PLCs may exhibit different biochemical properties. Millimolar levels of $\mathrm{Ca}^{2+}$, as well as $\mathrm{Mn}^{2+}$ and $\mathrm{Co}^{2+}$, inhibited wheat PI-PLC activity toward $\mathrm{PI}(4,5) \mathrm{P}_{2}$, but promoted the activity toward PI(4)P [206]. The $\mathrm{pH}$ optimum for wheat PI-PLC is $\mathrm{pH}$ 6-7 for $\mathrm{PI}(4) \mathrm{P}$ and $\mathrm{pH}$ 6-6.5 for $\mathrm{PI}(4,5) \mathrm{P}_{2}$ [206]. Under 
micromolar $\mathrm{Ca}^{2+}$, P. patens PpPLC1 prefers $\mathrm{PI}(4,5) \mathrm{P}_{2}$ as substrate, whereas PpPLC2 displays no such selectivity. Under millimolar levels of $\mathrm{Ca}^{2+}$, PI was hydrolyzed by PpPLC2, but not by PpPLC1 [195]. Potato StPLC1, StPLC2, and StPLC3 toward PI $(4,5) \mathrm{P}_{2}$ were activated at $10 \mathrm{mM} \mathrm{Ca}^{2+}$, but were inhibited by $\mathrm{Al}^{3+}$. Lily (Lilium daviddi) LdPI-PLC is also activated by calmodulin (CaM). Application of CaM enhances PI-PLC activity, whereas anti-CaM antibody suppressed this effect [192].

PI-PLC activity is also regulated by other effectors (Fig. 8). Unlike animal PLC $\beta$ or PLC $\varepsilon$ [207, 208], plant PI-PLCs lack the conserved sequences involved in interacting with G proteins [205], but they are still regulated by $\mathrm{G}$ proteins. G $\alpha 1$ is able to bind to the $\mathrm{C} 2$ domain of PI-PLC in Pisum sativum as indicated by yeast two-hybrid assay [209]. Wheat PI-PLC1 interacts with the GA3, the canonical G $\alpha$ subunit of the heterotrimeric G protein, when expressed in tobacco epidermal tissue [182]. LdPI-PLC is activated by $\mathrm{G}$ protein agonist cholera toxin, and suppressed by $\mathrm{G}$ protein antagonist pertussis toxin [192]. Animal PI-PLC $\gamma$ is regulated by phosphorylation of tyrosine residues within the linker between the $\mathrm{X}$ and $\mathrm{Y}$ domains [200]. Several phosphorylation sites in the EF-hand motif and the $\mathrm{X}$ domain or the Y domain of Arabidopsis PI-PLC were identified by mass spectrometric peptide analyses [210]. Pea PI-PLC was activated by SA produced from heat acclimation [197]. Carrot PI-PLC was activated by wasp venom peptide mastoparan or the active analog Mas-7 [211] whereas neomycin $(100 \mu \mathrm{M})$ inhibiting the uptake of Mas-7 suppressed the Mas-7 stimulation of PI-PLC activity [211]. PI-PLC activity was stimulated by mastoparan in rhizobia/legume symbiosis [212]. Type-III phosphatidylinositol 4-kinases (PI4Ks) are necessary for PI-PLC activation as they provide the substrates such as $\mathrm{PI}(4) \mathrm{P}$ and $\mathrm{PI}(4,5) \mathrm{P}_{2}[213]$.

\subsubsection{Expression patterns and subcellular localization}

Most plant PI-PLCs are expressed in different developmental stages and various tissues such as leaves, roots, stems, flowers, and fruits. Most PI-PLCs in diverse plant species such as Arabidopsis, rice, wheat, rapeseed, tomato, maize, potato, lily, and mung bean are induced significantly by stress stimuli including drought, cold, salt, heat shock, ABA, and SA [180, 181, 184, 190, 196-198]. Rice OsPLC1 and $O S P L C 3$ were induced by salt, drought and cold stress, whereas the expression level of OSPLC4 was reduced under the stress conditions [142]. The analysis on the promoter region of OsPLCs revealed multiple cis elements such as ABA responsive element (ABRE), MYB binding site (MBS), Skn-1, RY-element, GCN4, TC-rich repeat and C-repeat/DRE [142].

PI-PLCs are detected in both membranes and cytosol as visualized by GFP-fused proteins and by subcellular fractionation in various plant species. But their subcellular localization may differ, depending on the enzymes and assay conditions. Arabidopsis AtPLC2, AtPLC9, and mung bean VrPLC3 are predominantly localized to the plasma membrane [180, 190, 203]. Rice OsPLCs and soybean PLCs are localized in both membrane and cytoplasm [142, 186, 214]. Wheat PI-PLC was associated with plasma membrane and ER [182]. BnPLC was only detected in a membrane fraction of mature and germinating rape seeds [215]. Two PI-PLCs are isolated from oat seedling, with one cytosolic and the other membrane-associated [191]. The PI-PLCs could be translocated between membrane and cytoplasm depending on $\mathrm{Ca}^{2+}$ concentrations in cells. As described in section 3.2.1, the C2 domain and EF hand of PI-PLC may be responsible for the membrane targeting [142, 190, 199]. 


\subsubsection{Cellular and physiological functions}

\subsubsection{Vesicle trafficking and pollen growth mediated by $\mathbf{P I P}_{2}$}

In geminating tobacco pollen tubes, PI-PLC accumulates in the plasma membrane near the tip, but not at the apex, whereas $\mathrm{PI}(4,5) \mathrm{P}_{2}$ exclusively accumulates at the apex of the pollen tube [216].

Disruption of PLC activity caused lateral spreading of PI $(4,5) \mathrm{P}_{2}$ from its apical plasma membrane, and also disrupted the $\mathrm{Ca}^{2+}$ gradient in pollen tube tips [216]. The $\mathrm{PI}(4,5) \mathrm{P}_{2}$ and $\mathrm{Ca}^{2+}$ gradients may play a critical role in maintaining the asymmetric membrane biogenesis and tip growth. $\mathrm{PI}(4,5) \mathrm{P}_{2}$ is involved in vesicle trafficking via membrane remodeling, changing protein activities and recruiting target proteins. In addition, $\mathrm{PI}(4,5) \mathrm{P}_{2}$ is also known to promote $\mathrm{PLD}$ activity which increases PA levels, as discussed in section 2.2 [217]. PA has been shown to be important for vesicle trafficking in pollen tubes, as described in section 2.5.4 [218].

\subsubsection{Gravitropic and hormone responses}

$\mathrm{IP}_{3}$ produced from PI-PLC activity has been proposed to be important for plant gravitropic and phototropic responses [219, 220]. Suppression of PI-PLC or overexpression of inositolphosphate 5-phosphatase decreased plant gravitropic response [206]. The involvement of $\mathrm{IP}_{3}$ in gravitropic response is probably mediated by $\mathrm{Ca}^{2+}$ to modulate calcium/CaM-dependent protein kinase (MCK1) activity, or mediated by inositol hexakisphosphate $\left(\mathrm{IP}_{6}\right)$ in modulating auxin receptor transport inhibitor response 1 (TIR1) (Fig. 8) [221, 222]. The loss of PpPLC1 resulted in insensitivity to cytokinin treatments and reduced gravitropic response. PpPLC1 knockout $P$. patens mutants also displayed a paler phenotype with decreased chlorophyll content and defect in chloroplasts, as compared to the filaments of wild-type [194]. Overexpressed BnPI-PLC2 in B. napus resulted in multiple effects, including enhanced photosynthesis, accelerated flowering time, and decreased maturation time with changes in hormonal distribution in different tissues [189]. Arabidopsis AtPI-PLC2 is involved in reproductive organ development. Loss of AtPI-PLC2 resulted in an elevated auxin level through enhancing transcript level of genes in auxin synthesis and auxin signaling, thus led to defective male and female gametophyte development [223].

\subsubsection{Cytoskeletal organization and stress tolerance}

Overexpression of $\mathrm{ZmPLCl}$ enhanced corn grain yield under drought conditions while suppression of ZmPLC1 had an opposite effect [193]. Overexpression of BnPLC2 also improved plant drought resistance in B. napus [189]. Both AtPLC3 and AtPLC9 play a positive role in thermo tolerance; knockout of AtPLC3 or AtPLC9 decreased heat tolerance [180, 224]. Suppression of SlPLC4 in tomato impaired the Avr/Cf-4 induced HR and enhanced colonization of Cf-4 in cells, and SIPLC4-overexpressing cells displayed an opposite effect [184]. SIPLC2 is required for xylanase-induced expression of $P R 1$ and $H S R 203 J$ related to defense response [225]. Wheat PI-PLC plays a positive role in microtubule formation in plasmolyzed cells in response to hyperosmotic stress, as demonstrated by a complete defect of tubulin polymers when PI-PLC activity was suppressed by an inhibitor [183]. In the condition favoring actin polymerization, PI-PLC in oat roots was associated with cytoskeleton, whereas PI-PLC was released to cytosol under actin depolymerization [191].

\subsubsection{Mechanisms of PI-PLC actions}

The activation of PI-PLC may result in the alterations of several important cellular mediators and lipid 
intermediates, including DAG, $\mathrm{PA}, \mathrm{PI}(4,5) \mathrm{P}_{2}, \mathrm{PI}(4) \mathrm{P}, \mathrm{IP}_{3}$, and $\mathrm{IP}_{6}$, thus impacting various cellular processes, such as signal transduction, vesicular trafficking, cytoskeleton dynamics, and membrane remodeling (Fig. 7). $\mathrm{IP}_{3}$ produced by the PI-PLC activity is important for $\mathrm{Ca}^{2+}$ signaling. In animal cells, $\mathrm{IP}_{3}$ triggers $\mathrm{Ca}^{2+}$ released from internal stores through its binding to $\mathrm{IP}_{3}$ receptor, thus activating a series of proteins regulated by $\mathrm{Ca}^{2+}$. In plants, $\mathrm{IP}_{3}$ is rapidly elevated and is accompanied by an increase in cytosolic $\mathrm{Ca}^{2+}$ in response to different stimuli, such as heat, salt, dehydration and cold stress $[180,189,220,226]$. However, $\mathrm{IP}_{3}$ receptor has not been identified in plants. One possibility is that $\mathrm{IP}_{3}$ is further phosphorylated into $\mathrm{IP}_{6}$ (Fig. 8). It has been reported that microinjected $\mathrm{IP}_{3}$ was rapidly converted into $\mathrm{IP}_{6}$ and the ability of $\mathrm{IP}_{6}$ to release $\mathrm{Ca}^{2+}$ was about 100 times more than that of $\mathrm{IP}_{3}[227]$.

In addition, the activity of PI-PLC affects the level and distribution of $\mathrm{PI}(4,5) \mathrm{P}_{2}$ and possibly PI(4)P and other polyphosphoinositides (PPIs), which themselves play important roles in diverse processes (Fig. 7).The concentration of PPIs in plant cells is very low, constituting less than $1 \%$ of total phospholipids in cells. $\mathrm{PI}(4,5) \mathrm{P}_{2}$ level is 20 - to 100 - fold lower than $\mathrm{PI}(4) \mathrm{P}$ in plant cells, but its level and distribution in the cell are highly dynamic $[228,229]$. $\mathrm{PI}(4,5) \mathrm{P}_{2}$ is an effector required for many PLD activities and regulates vesicle trafficking, membrane asymmetry, and tip growth [225-227]. $\mathrm{PI}(4) \mathrm{P}$ serves as a precursor for $\mathrm{PI}(4,5) \mathrm{P}_{2}$ synthesis and also as a substrate for PI-PLC. PI(4)P and other PPIs also function as messengers in cells [228].

The level of DAG produced by PI-PLC is very low as detected by DAG binding protein marker, C1 domain of human PKC [230]. In tobacco BY-2 cells or in Arabidopsis plants, the PI-PLC activity altered the DAG level in trans-Golgi membrane, but not in the plasma membrane. DAG involved in lipid metabolism occurs at inner leaflets of membranes of intracellular compartments such as the ER, plastid, and mitochondrion [230]. In animal cells, DAG in membranes recruits and activates PKC and other proteins [178]. As noted in section 3.1.5, canonical PKCs have not been identified in plants, and it is possible that, like NPC, the downstream targets of PI-PLC may be different from those of animals or DAG derived from PI-PLC activation may serve as precursor for lipid metabolism and membrane remodeling $[177,179]$.

\section{PA as lipid mediators and growth regulator}

As discussed earlier, the activation of PLD or PLC can lead to the production of PA that acts as a lipid mediator in numerous signaling events. One key mode of PA actions as a signaling molecule is via its direct interaction with proteins. The "electrostatic/hydrogen bond switch mechanism" has been proposed for PA binding with effector proteins, which also helps explain the specificity of proteins for PA over other anionic membrane phospholipids [117]. The electrostatic/hydrogen bond and availability of the hydrophobic area around the PA-binding region in a protein may determine the specificity of PA-protein binding [14, 231]. In addition, a local build-up of PA perturbs membrane structures and affects membrane budding, fusion, and vesicular trafficking. Furthermore, PA is a central intermediate in glycerolipid synthesis, including phospholipids, galactolipids, and TAGs. Recent results have provided evidence that PA directly modulates central carbon and lipid metabolism and trafficking. 


\subsection{PA production under stress and PA molecular species}

PA is a minor phospholipids, constituting approximately $1 \%$ of total glycerophospholipids, but its level changes dynamically particularly in response to stimuli, such as plant-microbe interactions [14, 232]. A rapid and biphasic accumulation of PA occurs in plants after pathogen attack or treatment with fungal elicitors, or during legume-rhizobia interaction [31, 56, 73, 75, 233-235].

Pathogen-induced PA can be generated through PLD and/or PLC-DGK-mediated reactions [89, 236] (Fig. 4). In some cases, PLC-DGK activities were suggested to contribute to the first, small increase of PA whereas PLD contributed to the second, large peak of PA [89]. The race-specific elicitor Avr4 from Cladosporium fulvum rapidly induces accumulation of PA in tomato via the sequential activity of PLC and DGK [234]. Some DGK genes are induced during different environmental stresses including microbial elicitation, suggesting that DGK, as a generator of PA, may play an important role in plant basal resistance $[237,238]$. However, current data indicate that PLDs produce the majority of pathogen-induced PA [56, 83-89]. Different PLDs may regulate the temporal and spatial production of specific PA pools, which may have distinctive functions [74, 75, 108]. The PA production appears to be essential to plant defense. Arabidopsis ecotype Pi-0 is resistant to Pst DC3000 (AvrBsT) primarily due to PA production by PLD activity; the resistance is lost in the phospholipase $\mathrm{A}_{2}\left(\mathrm{PLA}_{2}\right)$ mutant SOBER1 [84]. The PA production suppressed by the PLA 2 SOBER1 in wild-type plants is required for AvrBsT-elicited HR in Pi-0. A $N$. benthamiana mutant with silenced PAP2 showed an increased PA level and enhanced resistance to Ralstonia solanacearum, via NADPH oxidase-dependent ROS over-accumulation and the increased JA-dependent defensive gene expression [235].

PA is comprised of various molecular species due to the carbon chain length and number of double bonds. Different acyl species affect PA interaction with proteins with different properties. Binding assays indeed showed PA target proteins have varying binding preferences to different PA molecular species $[50,65,99,239,240]$. Such a specific interaction and its biological significance are supported by structural demonstration. For example, the hydrophobic residues at the C-terminus of AtCP are inserted into the lipid bilayer containing PA, and this interaction is likely to be regulated by the length of the PA acyl chains [241, 242]. PA species and their generation in different membranes of subcellular compartments may confer specific functions. PA is present in various membranes, including the plasma membrane, chloroplast, ER, or the nuclear envelope. The ER contains the largest PA pool in plant cells, followed by the chloroplast, the cytoplasm, and the mitochondria [75]. Changes in PA levels in specific membranes directly affect the PA-targeted proteins, their localization, activity, and biological functions, as discussed in the next section.

\subsection{PA interaction with proteins and effects of the interactions}

PA has been reported to bind to various proteins, including transcriptional factors, protein kinases, lipid kinases, protein phosphatases, and proteins involved in vesicular trafficking and cytoskeletal rearrangement. Proteomic studies using PA-affinity pull-down followed by mass spectrometric analyses identified additional putative PA-binding proteins in plants [99, 243]. The PA-protein interaction can have two major consequences: modulating catalytic activities and intracellular distribution. 


\subsubsection{PA modulation of enzyme activity}

PLD $\alpha 1$-derived PA binds to NADPH oxidase and ABI1 and these interactions regulate the activity of the proteins in Arabidopsis response to ABA [47, 50]. A crosstalk between PLD/PA-mediated ABA signaling pathway and sphingosine kinase (SPHK)/phytosphingosine-1-phosphate (phyto-S1P)-mediated ABA signaling pathways has been established [41, 240]. PA directly interacts with two SPHKs and the PA binding promotes the substrate binding to the catalytic site of SPHK [240]. Meanwhile, the addition of phyto-S1P increases PLD activity. It is proposed that SPHK/phyto-S1P acts upstream of PLD/PA, and PA is involved in promoting SPHK activity to mediate ABA-induced stomatal closure [41, 64]. PA binds to the AGD7 [115]. The PA binding activates AGD7 hydrolysis of GTP in ARF, thus turning off ARF function. PLD and PA are also shown to be involved in regulation of root hair development. PA specifically binds to AtPDK1, which is involved in root hair growth and development [244]. On the other hand, PA binds to and inhibits the kinase activity of constitutive triple response 1 (CTR1) which is a negative regulator of ethylene [239].

\subsubsection{PA interaction with proteins regulating cytoskeleton dynamics}

AtCP, a key regulator of actin filament polymerization, binds to the barbed ends of actin filaments and blocks the growth of actin filaments. PA binds to AtCP and the binding inhibits the actin-binding activity of AtCP and disables the AtCP function, thereby stimulating actin polymerization from a large pool of profilin-actin [241, 242]. Exogenous PA application increased filamentous actin levels in Arabidopsis suspension cells and poppy pollen grains. Studies, using live-cell imaging of cytoskeletal dynamics and reverse-genetic analyses, further provide in vivo evidence for PA binding and inhibition of AtCP. This PA effect allows rapid actin polymerization and increases in filament abundance following stimulation [245]. Actin depolymerization often leads to the enhanced susceptibility to the invading pathogen [246]. Recent studies further showed that PA production is required for MAMP-induced actin remodeling [246]. As a convergence point for basal defense machinery, MAMP-stimulated actin remodeling is due to the inhibition of AtCP by PA; AtCP promotes resistance against bacterial and fungal pathogens [246]. Therefore, AtCP is a central target for the plant innate immune response. Disruption of actin cytoskeleton leads to the induction of defense response, such as SA-dependent expression of gene for PRs, and SA or latrunculin B treatment cause disruption of actin filaments, which can be prevented by PA application [247]. In other words, AtCP may act as a PA biosensor and a key transducer of membrane phospholipid remodeling signals into the changes in actin cytoskeleton dynamics. Under salt stress, PA produced by PLD $\alpha 1$ binds to MAP65-1, a microtubule stabilizing protein, to promote its ability of microtubule-polymerization and bundling [65].

\subsubsection{PA modulation of subcellular associations of proteins}

\subsubsection{Tethering protein to membrane}

Another key mode of PA action is to tether proteins to the membrane, thus modulating the protein's intracellular location and protein-protein association. The stimulus-induced increase in PA is associated with membranes [14]. In the PA-ABI1 interaction, PA tethers ABI1 to the plasma membrane and decreases its translocation to the nucleus (Fig. 3) [50]. Under salt stress, PA binds a cytosolic GAPC and recruits it to the membrane [248]. In auxin response, PA stimulates PP2A activity 
at membrane [93]. PA binds to a cytoplasmic region of the integral membrane protein NADPH oxidase to promote the production of ROS in plants [47]. Thus, in addition to the intracellular translocation of soluble proteins to the membranes, PA tethering also modulates the membrane association of cytosolic regions of integral membrane proteins.

\subsubsection{PA modulation of protein nuclear localization}

Protein translocation to the nucleus plays critical roles in regulating many cellular processes. PA can promote or inhibit protein localization to the nucleus, depending on the specific protein (Fig. 9). For example, PA in the ER binds to the transcriptional repressor OVERPRODUCER OF INOSITOL PROTEIN 1 (Opilp) and keeps it out of the nucleus in yeast (Fig. 8) [249]. This PA tethering relieves the transcriptional suppression so membrane lipid synthesis will increase. The de novo lipid biosynthesis will consume PA, which releases Opilp that enters the nucleus to suppress lipid production. PA decreases the translocation of ABI1 into the nucleus where it binds to ARABIDOPSIS THALIANA HOMEOBOX PROTEIN 6 (ATHB6), a transcription factor that negatively regulates ABA responses [50] (Fig. 9). PA can directly interact with the MYB transcription factor WEREWOLF (WER) that does not have a detectable nuclear localization signal based on its amino acid sequence [250]. The interaction is necessary for WER's nuclear localization [250, 251] (Fig. 9).The PA interaction may tether WER to the nuclear membrane and this tethering is necessary for the localization of the proteins from the cytosol to the nucleus. The different effects of PA are likely to be determined by the location and source of PA on the membranes, as well as other factors associated with the PA-binding proteins. In the PA-Opilp interaction, PA on the ER is metabolized for de novo lipid biosynthesis, whereas in the PA-WER interaction, PLD contributes to the production of PA. The spatial and temporal production of PA by PLD may result in the different effects of PA on the nuclear localization of its target proteins.

\subsection{PA effect on membrane structures}

Some of the cellular effects of PA have been proposed to result from its structural alterations on cellular membranes. PA is a hexagonal type II, cone-shape anionic lipid, and has the propensity to form a loosened structure around PA, thus exposing the hydrophobic zone of membrane lipids to the effector proteins $[252,253]$. For example, proteins with hydrophobic regions can insert into the bilayer and bind to PA. In addition, an increase in the cone-shaped PA in the lipid bilayer induces negative curvature, which is usually found at the neck of a vesicle during the process of fusing to an acceptor or budding from a donor membrane [253].Thus, through its structural effect, PA may affect membrane-protein interactions, and membrane budding and fusion (Fig. 6).

\subsection{PA modulation of lipid trafficking and metabolism}

In plants, fatty acids are synthesized exclusively in the plastid and then exported to the ER for the synthesis of glycerolipids. Some of the glycerolipids are transported back to the plastid where they are used for the synthesis of galactolipids and sulfolipids, the abundant and essential components of photosynthetic membranes [254]. The proteins involved in the ER-to-plastid lipid transport, trigalactosyldiacylglycerol (TGD) 2 and TGD4, bind PA [255]. TDG1, 2, and 3 may form a complex in the inner plastid envelope membrane and work together with TGD4 for glycerolipid transport from the ER into the chloroplast. In addition, it has been reported that PA binds to and stimulates the 
activity of chloroplast monogalactosyldiacylglycerol (MGDG) synthase MGD1 that synthesizes MGDG, the major lipid component of thylakoid membranes [256]. The PA mediation of the interorganelle transport of lipids and PA stimulation of MGDG synthesis raise an intriguing question of whether PA regulates lipid production and photosynthetic membrane biogenesis.

PA, besides being an important signaling lipid molecule, is a membrane structural component and an essential metabolic precursor for synthesis of phospholipids, glycolipids, and neutral lipids [254, 257, 258]. Over-accumulation of PAs results in many cellular, physiological, and structural changes in plant or yeast cells. Arabidopsis plants that lost both PA phosphohydrolases, PAH1 and PAH2, accumulated an excessive amount of PA, which was accompanied by increased phospholipid biosynthesis and massive membrane overexpansion in the ER [259]. PA does so by activating CTP:phosphocholine cytidylyltransferase that mediates a rate-limiting step in PC biosynthesis [260].

In addition to lipid metabolism, PA has been implicated in regulating central carbohydrate metabolism. PA interacts with $\mathrm{C}_{4}$ phosphoenolpyruvate carboxylase (PEPC) and GAPC [99, 243, 248]. PA inhibits the activity of $\mathrm{C}_{4}$ PEPC, which catalyzes carboxylation of phosphoenolpyruvate to oxaloacetate, a reaction for the initial fixation of $\mathrm{CO}_{2}$ in photosynthesis in $\mathrm{C}_{4}$ plants. GAPC catalyzes a glycolytic, NAD-dependent conversion of glyceraldehyde-3-phosphate to 1,3-bisphosphoglycerate. Glycolysis breaks down glucose and provides a central link to energy production and cellular metabolism, such as the synthesis of fatty acids and amino acids. PA does not affect GAPC activity but promotes GAPC cleavage [99]. GAPC is found in the cytosol and nucleus, and its movement to the nucleus is promoted by oxidative stress. In response to salt stress, PA interacts with GAPC and recruits it to the membrane [248]. In mammalian cells, GAPDH, besides being a metabolic enzyme, has many regulatory functions including gene transcription, DNA replication, nuclear tRNA export, and DNA repair [261, 262]. Thus, PA interaction with metabolic enzymes may function as a key modulator coordinating cellular metabolism. In addition, the lipid-protein interactions may play a role in the conversion of some of the "classic" metabolic enzymes into regulatory proteins.

\section{Open questions and perspectives}

Tremendous progress has been made in recent years in various aspects of D- and C-types of phospholipases, however, our understanding of these enzymes in plants is far from complete. PLD is the most active family of phospholipases in plants, and its activity is particularly high during tissue homogenization, freezing-thawing, and wounding. In many earlier studies, the activity of PLD was associated with membrane deterioration and stress damages. Recent studies have indicated that PLD activity in the cell is highly regulated and the regulated activation of different PLDs plays important roles in PLD functions. A number of cellular effectors, such as $\mathrm{Ca}^{2+}, \mathrm{PI}(4,5) \mathrm{P}_{2}$, oleate, $\mathrm{G}$ protein, and $\mathrm{pH}$ have been identified as regulators, and different PLDs have different requirements for them. However, the precise mechanism by which different PLDs are activated and affect plant growth and development remains to be elucidated. For example, how are different PLDs activated when plant cells are exposed to a stimulus, such as $\mathrm{ABA}, \mathrm{H}_{2} \mathrm{O}_{2}$, phosphorus deprivation, or pathogen elicitors? The same questions can be asked for other classes of phospholipases. Answering such questions will help delineate specific signaling cascades in plant growth and stress responses. 
PA is recognized as a new class of signaling messengers involved in various plant processes. The identification of PA-binding proteins shed light on its action and the specific pathways in which PA is involved. However, unlike other lipid-binding domains, the protein motifs for PA binding are not well defined. It is possible that varied amino acid sequences, rather than common structural folds, are involved for PA binding. In addition, PA can be produced by different PLDs and DGKs that are connected to the activation of NPCs and/or PI-PLCs. The use of genetic alterations of specific phospholipases together with lipid analysis has proven powerful to help decipher the action of various PLDs and PLCs. However, to connect PA directly with a specific PLD or PLC activation is often difficult. Another aspect, which is often underappreciated and underexplored, is that PA molecular species have different functions.

DAG is a well-documented lipid messenger in animals but its signaling function in plants remains an open question. Recent studies of NPCs indicate that DAG itself, rather than conversion to PA, plays a role in plant signaling. Findings like these will rejuvenate the interest in determining the DAG functions. One major challenge is to identify the direct downstream targets of DAG. The placement of DAG in specific cellular responses will provide impetus for target identification. On the other hand, the water-soluble $\mathrm{IP}_{3}$, resulting from PI-PLC activation, is a potent messenger that plays an important role in $\mathrm{Ca}^{2+}$ mobilization in animals. The function of $\mathrm{IP}_{3}$ is currently being debated in plants; $\mathrm{IP}_{3}$ could be converted to $\mathrm{IP}_{6}$ that could be more potent in $\mathrm{Ca}^{2+}$ release. The identification of downstream targets of inositol-polyphosphates will help clarify the question and facilitate the investigation of the mechanisms of their action.

Phospholipases in plants share many fundamental properties with those in animals, and yet distinctive differences have been noted between plants and animals. The molecular and biochemical heterogeneities of the PLD family play important roles in their diverse functions in plants. Both plants and humans have PX/PH-PLDs. However, the major group of plant PLDs is C2-PLDs which consist of several subtypes. So far no C2-PLDs have been reported in animals. Mammalian cells contain mitochondrial PLDs [263], but this type of PLDs has not been identified in plants. Mammalian cells have six types of PI-PLCs $(\beta, \gamma, \delta, \varepsilon, \eta, \zeta)$ that play critical roles in a broad range of cellular processes, but plants have one type of PI-PLC that is similar to PI-PLC $\zeta$. On the other hand, plants have another family of PLCs, NPC, that share sequence similarity with bacterial PLC, no genes similar to NPCs, has been identified in mammalian cells. An appreciation of the differences will help the investigation and understanding of these enzymes and lipid signaling in plants.

The unique features of lipid signaling in plants, together with technical difficulties in measuring and manipulating signaling lipids in plant cells, present great challenges as well as opportunities. Many critical cellular events, including signal transduction, vesicular trafficking, cytoskeletal rearrangement, and secretion, involve the assembly of proteins to a given region on a membrane. Lipid mediators play a key role in the membrane association of proteins, and phospholipases regulate the location and timing for the production of many lipid mediators. An increasing number of studies have begun to integrate genetic manipulation, sensitive and quantitative lipid profiling, molecular interaction, and cellular and physiological analyses to determine the functions of phospholipases and their derived mediators. A better understanding of phospholipases has the potential to fill many 
critical gaps in current knowledge of signaling cascades that mediate plant growth, development, and stress responses.

\section{Acknowledgment}

The authors acknowledge grant supports from the US National Science Foundation (IOS-0818740, MCB-0922879), the US Department of Agriculture (2007-35318-18393), the US Department of Energy (DE-SC0001295; DE-AR0000202), National Natural Science Foundation of China (31470762, 30871303, 31271514), the Chinese National Key Basic Research Project (2012CB114200), the Major State Basic Research Development Program of China (2013CB127001), and the Fundamental Research Funds for the Central Universities (2013PY065, 2662015PY090), and are grateful to Sherrie Trott for reading of the manuscript.

\section{References}

[1] Wang G, Ryu S, Wang X. Plant phospholipases: an overview. Methods Mol Biol 2012;861:123-37.

[2] Wang X. Plant phospholipases. Annu Rev Plant Physiol Plant Mol Biol 2001;52:211-231.

[3] Wang X. Lipid signaling. Curr Opin Plant Biol 2004;7:329-36.

[4] Hanahan DJ, Chaikoff IL. A new phospholipide-splitting enzyme specific for the ester linkage between the nitrogenous base and the phosphoric acid grouping. J Biol Chem 1947;169:699-705.

[5] Cockcroft S. $\mathrm{Ca}^{2+}$-dependent conversion of phosphatidylinositol to phosphatidate in neutrophils stimulated with fMet-Leu-Phe or ionophore A23187. Biochim Biophys Acta 1984;795:37-46.

[6] Bocckino SB, Blackmore PF, Wilson PB, Exton JH. Phosphatidate accumulation in hormone-treated hepatocytes via a phospholipase D mechanism. J Biol Chem 1987;262:15309-15.

[7] Wang X, Dyer JH, Zheng L. Purification and immunological analysis of phospholipase D from castor bean endosperm. Arch Biochem Biophys 1993;306:486-94.

[8] Wang X, Xu L, Zheng L. Cloning and expression of phosphatidylcholine-hydrolyzing phospholipase D from Ricinus communis L. J Biol Chem 1994;269:20312-7.

[9] Hammond SM, Altshuller YM, Sung TC, Rudge SA, Rose K, Engebrecht J, et al. Human ADP-ribosylation factor-activated phosphatidylcholine-specific phospholipase $\mathrm{D}$ defines a new and highly conserved gene family. J Biol Chem 1995;270:29640-3.

[10] Rose M, Kiesau P, Proft M, Entian KD. Sequence and functional analysis of a $7.2 \mathrm{~kb}$ DNA fragment containing four open reading frames located between RPB5 and CDC28 on the right arm of chromosome II. Yeast 1995;11:865-71.

[11] Pappan K, Qin W, Dyer JH, Zheng L, Wang X. Molecular cloning and functional analysis of polyphosphoinositide-dependent phospholipase D, PLD $\beta$, from Arabidopsis. J Biol Chem 1997;272:7055-61.

[12] Wang C, Wang X. A novel phospholipase D of Arabidopsis that is activated by oleic acid and associated with the plasma membrane. Plant Physiol 2001;127:1102-12.

[13] Wang X. Regulatory functions of phospholipase D and phosphatidic acid in plant growth, development, and stress responses. Plant Physiol 2005;139:566-73.

[14] Wang X, Devaiah SP, Zhang W, Welti R. Signaling functions of phosphatidic acid. Prog Lipid Res 2006;45:250-78.

[15] Eliás M, Potocký M, Cvrcková F, Zárský V. Molecular diversity of phospholipase D in 
angiosperms. BMC Genomics 2002;3:2.

[16] Qin C, Wang X. The Arabidopsis phospholipase D family. Characterization of a calcium-independent and phosphatidylcholine-selective PLD $\zeta 1$ with distinct regulatory domains. Plant Physiol 2002;128:1057-68.

[17] Zheng L, Krishnamoorthi R, Zolkiewski M, Wang X. Distinct $\mathrm{Ca}^{2+}$ binding properties of novel C2 domains of plant phospholipase $\mathrm{D} \alpha$ and $\beta$. J Biol Chem 2000;275:19700-6.

[18] Cheever ML, Sato TK, de Beer T, Kutateladze TG, Emr SD, Overduin M. Phox domain interaction with PtdIns(3)P targets the Vam7 t-SNARE to vacuole membranes. Nat Cell Biol 2001;3:613-8.

[19] Hiroaki H, Ago T, Ito T, Sumimoto H, Kohda D. Solution structure of the PX domain, a target of the SH3 domain. Nat Struct Biol 2001;8:526-30.

[20] Kanai F, Liu H, Field SJ, Akbary H, Matsuo T, Brown GE, et al. The PX domains of p47phox and p40phox bind to lipid products of PI(3)K. Nat Cell Biol 2001;3:675-8.

[21] Sung TC, Altshuller YM, Morris AJ, Frohman MA. Molecular analysis of mammalian phospholipase D2. J Biol Chem 1999;274:494-502.

[22] Sung TC, Zhang Y, Morris AJ, Frohman MA. Structural analysis of human phospholipase D1. J Biol Chem 1999;274:3659-66.

[23] Koonin EV. A duplicated catalytic motif in a new superfamily of phosphohydrolases and phospholipid synthases that includes poxvirus envelope proteins. Trends Biochem Sci 1996;21:242-3.

[24] Sung TC, Roper RL, Zhang Y, Rudge SA, Temel R, Hammond SM, et al. Mutagenesis of phospholipase D defines a superfamily including a trans-Golgi viral protein required for poxvirus pathogenicity. EMBO J 1997;16:4519-30.

[25] Gottlin EB, Rudolph AE, Zhao Y, Matthews HR, Dixon JE. Catalytic mechanism of the phospholipase D superfamily proceeds via a covalent phosphohistidine intermediate. Proc Natl Acad Sci 1998;95:9202-7.

[26] Zheng L, Shan J, Krishnamoorthi R, Wang X. Activation of plant phospholipase D $\beta$ by phosphatidylinositol 4,5-bisphosphate: characterization of binding site and mode of action. Biochemistry 2002;41:4546-53.

[27] Kusner DJ, Barton JA, Wen KK, Wang X, Rubenstein PA, Iyer SS. Regulation of phospholipase $\mathrm{D}$ activity by actin. Actin exerts bidirectional modulation of mammalian phospholipase $\mathrm{D}$ activity in a polymerization-dependent, isoform-specific manner. J Biol Chem 2002;277:50683-92.

[28] Zhao J, Wang X. Arabidopsis phospholipase D $\alpha 1$ interacts with the heterotrimeric G-protein $\alpha$-subunit through a motif analogous to the DRY motif in G-protein-coupled receptors. J Biol Chem 2004;279:1794-800.

[29] Pappan K, Zheng S, Wang X. Identification and characterization of a novel plant phospholipase $\mathrm{D}$ that requires polyphosphoinositides and submicromolar calcium for activity in Arabidopsis. $\mathrm{J}$ Biol Chem 1997;272:7048-54.

[30] Pappan K, Zheng L, Krishnamoorthi R, Wang X. Evidence for and characterization of $\mathrm{Ca}^{2+}$ binding to the catalytic region of Arabidopsis thaliana phospholipase D $\beta$. J Biol Chem 2004;279:47833-9.

[31] Li M, Hong Y, Wang X. Phospholipase D- and phosphatidic acid-mediated signaling in plants. 
Biochim Biophys Acta 2009;1791:927-35.

[32] Qin C, Wang C, Wang X. Kinetic analysis of Arabidopsis phospholipase D $\delta$. Substrate preference and mechanism of activation by $\mathrm{Ca}^{2+}$ and phosphatidylinositol 4,5-biphosphate. J Biol Chem 2002;277:49685-90.

[33] Pappan K, Wang X. Plant phospholipase D $\alpha$ is an acidic phospholipase active at near-physiological $\mathrm{Ca}^{2+}$ concentrations. Arch Biochem Biophys 1999;368:347-53.

[34] Austin-Brown SL, Chapman KD. Inhibition of phospholipase D $\alpha$ by N-acylethanolamines. Plant Physiol 2002;129:1892-8.

[35] Hong Y, Devaiah SP, Bahn SC, Thamasandra BN, Li M, Welti R, et al. Phospholipase De and phosphatidic acid enhance Arabidopsis nitrogen signaling and growth. Plant J 2009;58:376-87.

[36] Hong Y, Pan X, Welti R, Wang X. Phospholipase D $\alpha 3$ is involved in the hyperosmotic response in Arabidopsis. Plant Cell 2008;20:803-16.

[37] Fan L, Zheng S, Cui D, Wang X. Subcellular distribution and tissue expression of phospholipase $\mathrm{D} \alpha, \mathrm{D} \beta$, and $\mathrm{D} \gamma$ in Arabidopsis. Plant Physiol 1999;119:1371-8.

[38] Wang C, Zien CA, Afitlhile M, Welti R, Hildebrand DF, Wang X. Involvement of phospholipase $\mathrm{D}$ in wound-induced accumulation of jasmonic acid in Arabidopsis. Plant Cell 2000;12:2237-46.

[39] Zien CA, Wang C, Wang X, Welti R. In vivo substrates and the contribution of the common phospholipase D, PLD $\alpha$, to wound-induced metabolism of lipids in Arabidopsis. Biochim Biophys Acta 2001;1530:236-48.

[40] Yamaryo Y, Dubots E, Albrieux C, Baldan B, Block MA. Phosphate availability affects the tonoplast localization of PLD $\zeta 2$, an Arabidopsis thaliana phospholipase D. FEBS Lett 2008;582:685-90.

[41] Guo L, Mishra G, Markham JE, Li M, Tawfall A, Welti R, et al. Connections between sphingosine kinase and phospholipase D in the abscisic acid signaling pathway in Arabidopsis. $\mathrm{J}$ Biol Chem 2012;287:8286-96.

[42] Katagiri T, Takahashi S, Shinozaki K. Involvement of a novel Arabidopsis phospholipase D, AtPLD $\delta$, in dehydration-inducible accumulation of phosphatidic acid in stress signalling. Plant $\mathrm{J}$ 2001;26:595-605.

[43] Bargmann BOR, Laxalt AM, ter Riet B, van Schooten B, Merquiol E, Testerink C, et al. Multiple PLDs required for high salinity and water deficit tolerance in plants. Plant Cell Physiol 2009;50:78-89.

[44] Li W, Li M, Zhang W, Welti R, Wang X. The plasma membrane-bound phospholipase D $\delta$ enhances freezing tolerance in Arabidopsis thaliana. Nat Biotechnol 2004;22:427-33.

[45] Li M, Welti R, Wang X. Quantitative profiling of Arabidopsis polar glycerolipids in response to phosphorus starvation. Roles of phospholipases $\mathrm{D} \zeta 1$ and $\mathrm{D} \zeta 2$ in phosphatidylcholine hydrolysis and digalactosyldiacylglycerol accumulation in phosphorus-starved plants. Plant physiology 2006;142:750-61.

[46] Ohashi Y, Oka A, Rodrigues-Pousada R, Possenti M, Ruberti I, Morelli G, et al. Modulation of phospholipid signaling by GLABRA2 in root-hair pattern formation. Science 2003;300:1427-30.

[47] Zhang Y, Zhu H, Zhang Q, Li M, Yan M, Wang R, et al. Phospholipase D $\alpha 1$ and phosphatidic acid regulate NADPH oxidase activity and production of reactive oxygen species in ABA-mediated stomatal closure in Arabidopsis. Plant Cell 2009;21:2357-77.

[48] Yu L, Nie J, Cao C, Jin Y, Yan M, Wang F, et al. Phosphatidic acid mediates salt stress response 
by regulation of MPK6 in Arabidopsis thaliana. New Phytol 2010;188:762-73.

[49] Yu HQ, Yong TM, Li HJ, Liu YP, Zhou SF, Fu FL, et al. Overexpression of a phospholipase D $\alpha$ gene from Ammopiptanthus nanus enhances salt tolerance of phospholipase D $\alpha 1$-deficient Arabidopsis mutant. Planta 2015. Epub 2015 Aug 30.

[50] Zhang W, Qin C, Zhao J, Wang X. Phospholipase Da1-derived phosphatidic acid interacts with ABI1 phosphatase $2 \mathrm{C}$ and regulates abscisic acid signaling. Proc Natl Acad Sci USA 2004;101:9508-13.

[51] Mishra G, Zhang W, Deng F, Zhao J, Wang X. A bifurcating pathway directs abscisic acid effects on stomatal closure and opening in Arabidopsis. Science 2006;312:264-6.

[52] Pleskot R, Potocký M, Pejchar P, Linek J, Bezvoda R, Martinec J, et al. Mutual regulation of plant phospholipase D and the actin cytoskeleton. Plant J 2010;62:494-507.

[53] Gardiner JC, Harper JD, Weerakoon ND, Collings DA, Ritchie S, Gilroy S, et al. A 90-kD phospholipase D from tobacco binds to microtubules and the plasma membrane. Plant Cell 2001;13:2143-58.

[54] Zhang W, Wang C, Qin C, Wood T, Olafsdottir G, Welti R, et al. The oleate-stimulated phospholipase D, PLD $\delta$, and phosphatidic acid decrease $\mathrm{H}_{2} \mathrm{O}_{2}$-induced cell death in Arabidopsis. Plant Cell 2003;15:2285-95.

[55] Distéfano AM, Valiñas MA, Scuffi D, Lamattina L, Ten Have A, García-Mata C, et al. Phospholipase D $\delta$ knock-out mutants are tolerant to severe drought stress. Plant Signal Behav 2015. Epub 2015 Sep 4.

[56] Zhao J, Devaiah SP, Wang C, Li M, Welti R, Wang X. Arabidopsis phospholipase D $\beta 1$ modulates defense responses to bacterial and fungal pathogens. New Phytol 2013;199:228-40.

[57] Pinosa F, Buhot N, Kwaaitaal M, Fahlberg P, Thordal-Christensen H, Ellerström M, et al. Arabidopsis phospholipase $\mathrm{D} \delta$ is involved in basal defense and nonhost resistance to powdery mildew fungi. Plant Physiol 2013;163:896-906.

[58] Lu S, Yao S, Wang G, Guo L, Zhou Y, Hong Y, et al. Phospholipase De enhances Braasca napus growth and seed production in response to nitrogen availability. Plant Biotechnol J 2015. Epub 2015 Aug 11.

[59] Zhao J, Wang C, Bedair M, Welti R, Sumner LW, Baxter I, et al. Suppression of phospholipase D $\gamma$ s confers increased aluminum resistance in Arabidopsis thaliana. PLoS One 2011;6:e28086.

[60] Cruz-Ramírez A, Oropeza-Aburto A, Razo-Hernández F, Ramírez-Chávez E, Herrera-Estrella L. Phospholipase DZ2 plays an important role in extraplastidic galactolipid biosynthesis and phosphate recycling in Arabidopsis roots. Proc Natl Acad Sci USA 2006;103:6765-70.

[61] Li G, Xue HW. Arabidopsis PLD $\zeta 2$ regulates vesicle trafficking and is required for auxin response. Plant Cell 2007;19:281-95.

[62] Uraji M, Katagiri T, Okuma E, Ye W, Hossain MA, Masuda C, et al. Cooperative function of PLD $\delta$ and PLD $\alpha 1$ in abscisic acid-induced stomatal closure in Arabidopsis. Plant Physiol 2012; 159:450-60.

[63] Distéfano AM, Scuffi D, García-Mata C, Lamattina L, Laxalt AM. Phospholipase D $\delta$ is involved in nitric oxide-induced stomatal closure. Planta 2012;236:1899-907.

[64] Guo L, Devaiah SP, Narasimhan R, Pan X, Zhang Y, Zhang W, et al. Cytosolic glyceraldehyde-3-phosphate dehydrogenases interact with phospholipase $\mathrm{D} \delta$ to transduce hydrogen peroxide signals in the Arabidopsis response to stress. Plant Cell 2012;24:2200-12. 
[65] Zhang Q, Lin F, Mao T, Nie J, Yan M, Yuan M, et al. Phosphatidic acid regulates microtubule organization by interacting with MAP65-1 in response to salt stress in Arabidopsis. Plant Cell 2012;24:4555-76.

[66] Hong Y, Zhang W, Wang X. Phospholipase D and phosphatidic acid signalling in plant response to drought and salinity. Plant Cell Environ 2010;33:627-35.

[67] Boller T, Felix G. A renaissance of elicitors: perception of microbe-associated molecular patterns and danger signals by pattern-recognition receptors. Annu Rev Plant Biol 2009;60:379-406.

[68] Dodds PN, Rathjen JP. Plant immunity: towards an integrated view of plant-pathogen interactions. Nat Rev Genetics 2010;11:539-48.

[69] Elmore JM, Liu J, Smith B, Phinney B, Coaker G. Quantitative proteomics reveals dynamic changes in the plasma membrane during Arabidopsis immune signaling. Mol Cell Proteomics 2012;11:M111.

[70] Zhao J, Davis LC, Verpoorte R. Elicitor signal transduction leading to production of plant secondary metabolites. Biotechnol Adv 2005;23:283-333.

[71] KazanK, Lyons R. Intervention of phytohormone pathways by pathogen effectors. Plant Cell 2014;26:2285-309.

[72] Tsuda K, Katagiri F. Comparing signaling mechanisms engaged in pattern-triggered and effector-triggered immunity. Curr Opin Plant Biol 2010;13:459-65.

[73] Zhao J. Phospholipase D and phosphatidic acid in plant defence response: from protein-protein and lipid-protein interactions to hormone signaling. J Exp Bot 2015;66:1721-36.

[74] Meijer HJ, Munnik T. Phospholipid-based signaling in plants. Annu Rev Plant Biol 2003;54:265-306.

[75] Testerink C, Munnik T. Molecular, cellular, and physiological responses to phosphatidic acid formation in plants. J Exp Bot 2011;62:2349-61.

[76] Young SA, Wang X, Leach JE. Changes in the plasma membrane distribution of rice phospholipase D during resistant interactions with Xanthomonas oryzae pv oryzae. Plant Cell 1996;8:1079-90.

[77] Camehl I, Drzewiecki C, Vadassery J, Shahollari B, Sherameti I, Forzani C, et al. The OXI1 kinase pathway mediates Piriformospora indica-induced growth promotion in Arabidopsis. PLoS Pathog 2011;7:e1002051.

[78] Zhao J, Wang X. Biochemical analysis of the interaction between phospholipase D 1 and GTP-binding protein $\alpha$-subunit from Arabidopsis thaliana. Methods Mol Biol 2013;1043:21-35.

[79] Suharsono U, Fujisawa Y, Kawasaki T, Iwasaki Y, Satoh H, Shimamoto K. The heterotrimeric G protein $\alpha$ subunit acts upstream of the small GTPase Rac in disease resistance of rice. Proc Natl Acad Sci USA 2002;99:13307-12.

[80] Llorente F, Alonso-Blanco C, Sanchez-Rodriguez C, Jorda L, Molina A. ERECTA receptor-like kinase and heterotrimeric $\mathrm{G}$ protein from Arabidopsis are required for resistance to the necrotrophic fungus Plectosphaerella cucumerina. Plant J 2005;43:165-80.

[81] Trusov Y, Rookes JE, Chakravorty D, Armour D, Schenk PM, Botella JR. Heterotrimeric G proteins facilitate Arabidopsis resistance to necrotrophic pathogens and are involved in jasmonate signaling. Plant Physiol 2006;140:210-20.

[82] Torres MA, Morales J, Sánchez-Rodríguez C, Molina A, Dang1 JL. Functional interplay between 
Arabidopsis NADPH oxidases and heterotrimeric G protein. Mol Plant Microbe Interact 2013;26:686-94.

[83] Bargmann BOR, Laxalt AM, ter Riet B, Schouten E, Van Leeuwen W, Dekker HL, et al. LePLD $\beta 1$ activation and relocalization in suspension-cultured tomato cells treated with xylanase. Plant J 2006;45:358-68.

[84] Kirik A, Mudgett MB. SOBER1 phospholipase activity suppresses phosphatidic acid accumulation and plant immunity in response to bacterial effector AvrBsT. Proc Natl Acad Sci USA 2009;106:20532-7.

[85] Yamaguchi T, Kuroda M, Yamakawa H, Ashizawa T, Hirayae K, Kurimoto L, et al. Suppression of a phospholipase $\mathrm{D}$ gene, OsPLD $\beta 1$, activates defense responses and increases disease resistance in rice. Plant Physiol 2009;150:308-19.

[86] van der Luit AH, Piatti T, Van Doorn A, Musgrave A, Felix G, Boller T, et al. Elicitation of suspension-cultured tomato cells triggers the formation of phosphatidic acid and diacylglycerol pyrophosphate. Plant Physiol 2000;123:1507-16.

[87] Laxalt AM, ter Riet B, Verdonk JC, Parigi L, Tameling WI, Vossen J, et al. Characterization of five tomato phospholipase D cDNAs: rapid and specific expression of LePLD $\beta 1$ on elicitation with xylanase. Plant J 2001;26:237-47.

[88] de Torres Zabela M, Fernandez-Delmond I, Niittyla T, Sanchez P, Grant M. Differential expression of genes encoding Arabidopsis phospholipases after challenge with virulent or avirulent Pseudomonas isolates. Mol Plant Microbe Interact 2002;15:808-16.

[89] Andersson MX, Kourtchenko O, Dangl JL, Mackey D, Ellerström M. Phospholipase-dependent signalling during the AvrRpm1- and AvrRpt2-induced disease resistance responses in Arabidopsis thaliana. Plant J 2006;47:947-59.

[90] Sang Y, Cui D, Wang X. Phospholipase D and phosphatidic acid-mediated generation of superoxide in Arabidopsis. Plant Physiol 2002;126:1449-58.

[91] Park J, Gu Y, Lee Y, Yang Z, Lee Y. Phosphatidic acid induces leaf cell death in Arabidopsis by activating the Rho-related small G protein GTPase-mediated pathway of reactive oxygen species generation. Plant Physiol 2004;134:129-36.

[92] Johansson ON, Fahlberg P, Karimi E, Nilsson AK, Ellerström M, Andersson MX. Redundancy among phospholipase D isoforms in resistance triggered by recognition of the Pseudomonas syringae effector AvrRpm1 in Arabidopsis thaliana. Front Plant Sci 2014;5:639.

[93] Gao HB, Chu YJ, Xue HW. Phosphatidic acid (PA) binds PP2AA1 to regulate PP2A activity and PIN1 polar localization. Mol Plant 2013;6:1692-702.

[94] Segonzac C, Macho AP, Sanmartín M, Ntoukakis V, Sánchez-Serrano JJ, Zipfel C. Negative control of BAK1 by protein phosphatase 2A during plant innate immunity. EMBO J 2014;33:1729-844.

[95] Wu P, Gao HB, Zhang LL, Xue HW, Lin WH. Phosphatidic acid regulates BZR1 activity and brassinosteroid signal of Arabidopsis. Mol Plant 2014;7:445-7.

[96] Kotel'nikova IM, Nekrasov EV, Krylov AV. Effect of tobacco mosaic virus on phospholipid content and phospholipase D activity in tobacco leaves. Russ J Plant Physiol 2004;51:63-9.

[97] Hyodo K, Taniguchi T, Manabe Y, Kaido M, Mise K, Sugawara T, et al. Phosphatidic acid produced by phospholipase D promotes RNA replication of a plant RNA virus. PLoS Pathog 2015;11:e1004909. 
[98] McLoughlin F, Galvan-Ampudia CS, Julkowska MM, Caarls L, van der Does D, Laurière C, et al. The Snf1-related protein kinases SnRK2.4 and SnRK2.10 are involved in maintenance of root system architecture during salt stress. Plant J 2012;72:436-49.

[99] Kim SC, Guo L, Wang X. Phosphatidic acid binds to cytosolic glyceraldehyde-3-phosphate dehydrogenase and promotes its cleavage in Arabidopsis. J Biol Chem 2013;288:11834-44.

[100] Gardiner J, Collings DA, Harper JD, Marc J. The effects of the phospholipase D-antagonist 1-butanol on seedling development and microtubule organisation in Arabidopsis. Plant Cell Physiol 2003;44:687-96.

[101] Jones D, Morgan C, Cockcroft S. Phospholipase D and membrane traffic. Potential roles in regulated exocytosis, membrane delivery and vesicle budding. Biochim Biophys Acta 1999;1439:229-44.

[102] Shin I, Kweon SM, Lee ZW, Kim SI, Joe CO, Kim JH, et al. Lysophosphatidic acid increases intracellular $\mathrm{H}_{2} \mathrm{O}_{2}$ by phospholipase D and RhoA in rat-2 fibroblasts. Mol Cells 1999;9:292-9.

[103] Kusner DJ, Barton JA, Qin C, Wang X, Iyer SS. Evolutionary conservation of physical and functional interactions between phospholipase D and actin. Arch Biochem Biophys 2003;412:231-241.

[104] Lee S, Park JB, Kim JH, Kim Y, Kim JH, Shin KJ, et al. Actin directly interacts with phospholipase D, inhibiting its activity. J Biol Chem 2001;276:28252-60.

[105] Dhonukshe P, Laxalt AM, Goedhart J, Gadella TW, Munnik T. Phospholipase D activation correlates with microtubule reorganization in living plant cells. Plant Cell 2003;15:2666-79.

[106] Ho AYY, Day DA, Brown MH, Marc J. Arabidopsis phospholipase D $\delta$ as an initiator of cytoskeleton-mediated signalling to fundamental cellular processes. Funct Plant Biol 2009;36:190-8.

[107] Andreeva Z, Ho A, Barthet M, Potocký M, Bezvoda R, Žárský V, et al. Phospholipase D family interactions with the cytoskeleton: isoform $\delta$ promotes plasma membrane anchoring of cortical microtubules. Funct Plant Biol 2009;36:600-12.

[108] Wang X, Guo L, Wang G, Li M. PLD: phospholipase Ds in plant signaling. In: Wang X, editor. Phospholipases in plant signaling, Signaling and communication in plants, Berlin, Heidelberg: Springer; 2014, p. 3-26.

[109] Lee S, Hirt H, Lee Y. Phosphatidic acid activates a wound-activated MAPK in Glycine max. Plant J 2001;26:479-86.

[110] Komati H, Fabio Naro F, Saida Mebarek S, De Arcangelis V, Adamo S, Lagarde M, et al. Phospholipase $\mathrm{D}$ is involved in myogenic differentiation through remodeling of actin cytoskeleton. Mol Biol Cell 2005;16:1232-44.

[111] McMahon HT, Gallop JL. Membrane curvature and mechanisms of dynamic cell membrane remodelling. Nature 2005;438:590-6.

[112] Donaldson JG. Phospholipase D in endocytosis and endosomal recycling pathways. Biochim Biophys Acta 2009;1791:845-9.

[113] El Kasmi F, Krause C, Hiller U, Stierhof Y-D, Mayer U, Conner L, et al. SNARE complexes of different composition jointly mediate membrane fusion in Arabidopsis cytokinesis. Mol Biol Cell 2013;24:1593-601.

[114] Nakanishi H, Morishita M, Schwartz CL, Coluccio A, Engebrecht J, Neiman AM. Phospholipase D and the SNARE Sso1p are necessary for vesicle fusion during sporulation in 
yeast. J Cell Sci 2006;119:1406-15.

[115] Min MK, Kim SJ, Miao Y, Shin J, Jiang L, Hwang I. Overexpression of Arabidopsis AGD7 causes relocation of Golgi-localized proteins to the endoplasmic reticulum and inhibits protein trafficking in plant cells. Plant Physiol 2007;143:1601-14.

[116] Pleskot R, Li J, Zárský V, Potocký M, Staiger CJ. Regulation of cytoskeletal dynamics by phospholipase D and phosphatidic acid. Trends Plant Sci 2013;18:496-504.

[117] Kooijman EE, Tieleman DP, Testerink C, Munnik T, Rijkers DT, Burger KN, et al. An electrostatic/hydrogen bond switch as the basis for the specific interaction of phosphatidic acid with proteins. J Biol Chem 2007;282:11356-64.

[118] Yang JS, Gad H, Lee SY, Mironov A, Zhang L, Beznoussenko GV, et al. A role for phosphatidic acid in COPI vesicle fission yields insights into Golgi maintenance. Nat Cell Biol 2008;10:1146-53.

[119] Huang H, Frohman MA. Lipid signaling on the mitochondrial surface. Biochim Biophys Acta 2009;1791:839-44.

[120] Motes CM, Pechter P, Yoo CM, Wang YS, Chapman KD, Blancaflor EB. Differential effects of two phospholipase $\mathrm{D}$ inhibitors, 1-butanol and $\mathrm{N}$-acylethanolamine, on in vivo cytoskeletal organization and Arabidopsis seedling growth. Protoplasma 2005;226:109-23.

[121] Hirase A, Hamada T, Itoh TJ, Shimmen T, Sonobe S. n-Butanol induces depolymerization of microtubules in vivo and in vitro. Plant Cell Physiol 2006;47:1004-9.

[122] Langhans M, Robinson DG. 1-Butanol targets the Golgi apparatus in tobacco BY-2 cells, but in a different way to Brefeldin A. J Exp Bot 2007;58:3439-47.

[123] Wickner W. Membrane fusion: five lipids, four SNAREs, three chaperones, two nucleotides, and a Rab, all dancing in a ring on yeast vacuoles. Annu Rev Cell Dev Biol 2010;26:115-36.

[124] Delage E, Puyaubert J, Zachowski A, Ruelland E. Signal transduction pathways involving phosphatidylinositol 4-phosphate and phosphatidylinositol 4,5-bisphosphate: convergences and divergences among eukaryotic kingdoms. Prog Lipid Res 2013;52:1-14.

[125] Raucher D, Stauffer T, Chen W, Shen K, Guo S, York JD, et al. Phosphatidylinositol 4,5-bisphosphate functions as a second messenger that regulates cytoskeleton-plasma membrane adhesion. Cell 2000;100:221-8.

[126] Roach AN, Wang Z, Wu P, Zhang F, Chan RB, Yonekubo Y, et al. Phosphatidic acid regulation of PIPKI is critical for actin cytoskeletal reorganization. J Lipid Res 2012;53:2598-609.

[127] Allwood EG, Anthony RG, Smertenko AP, Reichelt S, Drobak BK, Doonan JH, et al. Regulation of the pollen-specific actin-depolymerizing factor L1ADF1. Plant Cell 2002;14:2915-27.

[128] Xiang Y, Huang X, Wang T, Zhang Y, Liu Q, Hussey PJ, et al. ACTIN BINDING PROTEIN 29 from Lilium pollen plays an important role in dynamic actin remodeling. Plant Cell 2007;19:1930-46.

[129] Saarikangas J, Zhao H, Lappalainen P. Regulation of the actin cytoskeleton-plasma membrane interplay by phosphoinositides. Physiol Rev 2010;90:259-89.

[130] Yin HL, Janmey PA. Phosphoinositide regulation of the actin cytoskeleton. Annu Rev Physiol 2003;65:761-89.

[131] Davis AJ, Im YJ, Dubin JS, Tomer KB, Boss WF. Arabidopsis phosphatidylinositol phosphate kinase 1 binds F-actin and recruits phosphatidylinositol 4-kinase $\beta 1$ to the actin cytoskeleton. $\mathrm{J}$ 
Biol Chem 2007;282:14121-31.

[132] Cockcroft S. Phosphatidic acid regulation of phosphatidylinositol 4-phosphate 5-kinases. Biochim Biophys Acta 2009;1791:905-12.

[133] Zhang Q, Xiao S. Lipids in salicylic acid-mediated defense in plants: focusing on the roles of phosphatidic acid and phosphatidylinositol 4-phosphate. Front Plant Sci 2015;6:387.

[134] Welti R, Li W, Li M, Sang Y, Biesiada H, Zhou HE, et al. Profiling membrane lipids in plant stress responses. Role of phospholipase D $\alpha$ in freezing-induced lipid changes in Arabidopsis. J Biol Chem 2002;277:31994-2002.

[135] Devaiah SP, Pan X, Hong Y, Roth M, Welti R, Wang X. Enhancing seed quality and viability by suppressing phospholipase D in Arabidopsis. Plant J 2007;50:950-7.

[136] Lee J, Welti R, Roth M, Schapaugh WT, Li J, Trick HN. Enhanced seed viability and lipid compositional changes during natural ageing by suppressing phospholipase $\mathrm{D} \alpha$ in soybean seed. Plant Biotechnol J 2012;10:164-73.

[137] Kates M. Hydrolysis of lecithin by plant plastid enzymes. Can J Biochem Physiol 1955;33:575-89.

[138] Rouet-Mayer MA, Valentova O, Simond-Côte E, Daussant J, Thévenot C. Critical analysis of phospholipid hydrolyzing activities in ripening tomato fruits. Study by spectrofluorimetry and high-performance liquid chromatography. Lipids 1995;30:739-46.

[139] Strauss H, Leibovitz-Ben Gershon Z, Heller M. Enzymatic hydrolysis of 1-monoacyl-SN-glycerol-3-phosphoryl-choline (1-lysolecithin) by phospholipases from peanut seeds. Lipids 1976;11:442-8.

[140] Nakamura Y, Awai K, Masuda T, Yoshioka Y, Takamiya KI, Ohta H. A novel phosphatidylcholine-hydrolyzing phospholipase $\mathrm{C}$ induced by phosphate starvation in Arabidopsis. J Biol Chem 2005;280:7469-76.

[141] Singh A, Kanwar P, Pandey A, Tyagi AK, Sopory SK, Kapoor S, et al. Comprehensive genomic analysis and expression profiling of phospholipase $\mathrm{C}$ gene family during abiotic stresses and development in rice. PLoS One 2013;8:e62494.

[142] Kuppusamy T, Giavalisco P, Arvidsson S, Sulpice R, Stitt M, Finnegan PM, et al. Lipid biosynthesis and protein concentration respond uniquely to phosphate supply during leaf development in highly phosphorus-efficient Hakea prostrata. Plant Physiol 2014;166:1891-911.

[143] Pokotylo I, Pejchar P, Potocký M, Kocourková D, Krčková Z, Ruelland E, et al. The plant non-specific phospholipase $\mathrm{C}$ gene family. Novel competitors in lipid signalling. Prog Lipid Res 2013;52:62-79.

[144] Peters C, Li M, Narasimhan R, Roth M, Welti R, Wang X. Nonspecific phospholipase C NPC4 promotes responses to abscisic acid and tolerance to hyperosmotic stress in Arabidopsis. Plant Cell 2010;22:2642-59.

[145] Peters C, Kim SC, Devaiah S, Li M, Wang X. Non-specific phospholipase C5 and diacylglycerol promote lateral root development under mild salt stress in Arabidopsis. Plant Cell Environ 2014;37:2002-13.

[146] Reddy VS, Rao DK, Rajasekharan R. Functional characterization of lysophosphatidic acid phosphatase from Arabidopsis thaliana. Biochim Biophys Acta 2010;1801:455-61.

[147] Scherer GF, Paul RU, Holk A, Martinec J. Down-regulation by elicitors of phosphatidylcholine-hydrolyzing phospholipase $\mathrm{C}$ and up-regulation of phospholipase $\mathrm{A}$ in 
plant cells. Biochem Biophys Res Commun 2002;293:766-70.

[148] Nakamura Y, Ohta $H$. The diacylglycerol forming pathways differ among floral organs of Petunia hybrida. FEBS Lett 2007;581:5475-9

[149] Pejchar P, Potocký M, Novotná Z, Veselková S, Kocourková D, Valentová O, et al. Aluminium ions inhibit the formation of diacylglycerol generated by phosphatidylcholine-hydrolysing phospholipase C in tobacco cells. New Phytol 2010;188:150-60.

[150] Pejchar P, Potocký M, Krčková Z, Brouzdová J, Daněk M, Martinec J. Non-specific phospholipase $\mathrm{C} 4$ mediates response to aluminum toxicity in Arabidopsis thaliana. Front Plant Sci 2015;6:66.

[151] Pejchar P, Martinec J. Aluminum ions alter the function of non-specific phospholipase C through the changes in plasma membrane physical properties. Plant Signal Behav 2015. Epub 2015 May 29.

[152] Pokotylo IV, Kretynin SV, Khripach VA, Ruelland E, Blume YB, Kravets VS. Influence of 24-epibrassinolide on lipid signalling and metabolism in Brassica napus. Plant Growth Regul 2014;73:9-17.

[153] Wimalasekera R, Pejchar P, Holk A, Martinec J, Scherer GF. Plant phosphatidylcholine-hydrolyzing phospholipases C NPC3 and NPC4 with roles in root development and brassinolide signaling in Arabidopsis thaliana. Mol Plant 2010;3:610-25.

[154] Nakamura Y, Liu YC, Lin YC. Floral glycerolipid profiles in homeotic mutants of Arabidopsis thaliana. Biochem Biophys Res Commun 2014;450:1272-75.

[155] Gaude N, Nakamura Y, Scheible WR, Ohta H, Dörmann P. Phospholipase C5 (NPC5) is involved in galactolipid accumulation during phosphate limitation in leaves of Arabidopsis. Plant J 2008;56:28-39.

[156] Andersson MX, Larsson KE, Tjellström H, Liljenberg C, Sandelius AS. Phosphate-limited oat. The plasma membrane and the tonoplast as major targets for phospholipid-to-glycolipid replacement and stimulation of phospholipases in the plasma membrane. J Biol Chem 2005;280:27578-86.

[157] Janda M, Planchais S, Djafi N, Martinec J, Burketova L, Valentova O, et al. Phosphoglycerolipids are master players in plant hormone signal transduction. Plant Cell Rep 2013;32:839-51.

[158] Nakamura Y, Teo NZ, Shui G, Chua CH, Cheong WF, Parameswaran S, et al. Transcriptomic and lipidomic profiles of glycerolipids during Arabidopsis flower development. New Phytol 2014;203:310-22.

[159] Kocourková D, Krcková Z, Pejchar P, Veselková S, Valentová O, Wimalasekera R, et al. The phosphatidylcholine-hydrolysing phospholipase C NPC4 plays a role in response of Arabidopsis roots to salt stress. J Exp Bot 2011;62:3753-63.

[160] Carter C, Pan S, Zouhar J, Avila EL, Girke T, Raikhel NV. The vegetative vacuole proteome of Arabidopsis thaliana reveals predicted and unexpected proteins. Plant Cell 2004;16:3285-303.

[161] Härtel H, Dormann P, Benning C. DGD1-independent biosynthesis of extraplastidic galactolipids after phosphate deprivation in Arabidopsis. Proc Natl Acad Sci USA 2000;97:10649-54.

[162] Nakamura Y. Phosphate starvation and membrane lipid remodeling in seed plants. Prog Lipid Res 2013;52:43-50. 
[163] Pant BD, Burgos A, Pant P, Cuadros-Inostroza A, Willmitzer L, Scheible WR. The transcription factor PHR1 regulates lipid remodeling and triacylglycerol accumulation in Arabidopsis thaliana during phosphorus starvation. J Exp Bot 2015. Epub 2015 Feb 13.

[164] Krčková Z, Brouzdová J, Daněk M, Kocourková D, Rainteau D, Ruelland E, et al. Arabidopsis non-specific phospholipase $\mathrm{C} 1$ : characterization and its involvement in response to heat stress. Front Plant Sci 2015;6:928.

[165] Zhu JK. Salt and drought stress signal transduction in plants. Annu Rev Plant Biol 2002;53:247-73.

[166] Douce R, Joyard J. Chloroplast envelope lipids: detection and biosynthesis. Method Enzymol 1980;69:290-301.

[167] Dong W, Lv H, Xia G, Wang M. Does diacylglycerol serve as a signaling molecule in plants? Plant Signal Behav 2012;7:472-5.

[168] Kurosaki F, Tsurusawa Y, Nishi A. Breakdown of phosphatidylinositol during the elicitation of phytoalexin production in cultured carrot cells. Plant Physiol 1987;85:601-4.

[169] Lienart Y, Gautier C, Driguez H. Modulation of laminarinase activity by $\mathrm{Ca}^{2+}$, dcAMP, phorbol-ester and diacylglycerol in plant cells. Phytochemistry 1990;29:3735-8.

[170] Wang Y, Kandeler R. Promotion of flowering by a tumor promoter. J Plant Physiol 1994;144:710-3.

[171] Baudouin E, Charpenteau M, Ranjeva R, Ranty B. Involvement of active oxygen species in the regulation of a tobacco defence gene by phorbol ester. Plant Sci 1999;142:67-72.

[172] Baudouin E, Charpenteau M, Ranjeva R, Ranty B. A 45-kDa protein kinase related to mitogen-activated protein kinase is activated in tobacco cells treated with a phorbol ester. Planta 2002;214:400-5.

[173] Pierrugues O, Brutesco C, Oshiro J, Gouy M, Deveaux Y, Carman GM, et al. Lipid phosphate phosphatases in Arabidopsis. Regulation of the AtLPP1 gene in response to stress. J Biol Chem 2001;276:20300-8.

[174] França MG, Matos AR, D'arcy-Lameta A, Passaquet C, Lichtlé C, Zuily-Fodil Y, et al. Cloning and characterization of drought-stimulated phosphatidic acid phosphatase genes from Vigna unguiculata. Plant Physiol Biochem 2008;46:1093-100.

[175] Lee Y, Assmann SM. Diacylglycerols induce both ion pumping in patch-clamped guard-cell protoplasts and opening of intact stomata. Proc Natl Acad Sci USA 1991;88:2127-31.

[176] Berridge MJ. Inositol trisphosphate and calcium signalling. Nature 1993;361:315-25.

[177] Munnik T, Testerink C. Plant phospholipid signaling: "in a nutshell”. J Lipid Res 2009;50:S260-5.

[178] Bunney TD, Katan M. PLC regulation: emerging pictures for molecular mechanisms. Trends Biochem Sci 2011;36:88-96.

[179] Pokotylo I, Kolesnikov Y, Kravets V, Zachowski A, Ruelland E. Plant phosphoinositide-dependent phospholipases $\mathrm{C}$ : variations around a canonical theme. Biochimie. 2014;96:144-57.

[180] Zheng SZ, Liu YL, Li B, Shang ZL, Zhou RG, Sun DY. Phosphoinositide-specific phospholipase C9 is involved in the thermotolerance of Arabidopsis. Plant J 2012;69:689-700.

[181] Hirayama T, Ohto C, Mizoguchi T, Shinozaki K. A gene encoding a phosphatidylinositol-specific phospholipase $\mathrm{C}$ is induced by dehydration and salt stress in 
Arabidopsis thaliana. Proc Natl Acad Sci USA 1995;92:3903-7.

[182] Khalil HB, Wang Z, Wright JA, Ralevski A, Donayo AO, Gulick PJ. Heterotrimeric G $\alpha$ subunit from wheat (Triticum aestivum), GA3, interacts with the calcium-binding protein, $\mathrm{Clo3}$, and the phosphoinositide-specific phospholipase C, PI-PLC1. Plant Mol Biol 2011;77:145-58.

[183] Komis G, Galatis B, Quader H, Galanopoulou D, Apostolakos P. Phospholipase C signaling involvement in macrotubule assembly and activation of the mechanism regulating protoplast volume in plasmolyzed root cells of Triticum turgidum. New Phytol 2008;178:267-82.

[184] Vossen JH, Abd-El-Haliem A, Fradin EF, van den Berg GC, Ekengren SK, Meijer HJ, et al. Identification of tomato phosphatidylinositol-specific phospholipase-C (PI-PLC) family members and the role of PLC4 and PLC6 in HR and disease resistance. Plant J 2010;62:224-39.

[185] Chou WM, Shigaki T, Dammann C, Liu YQ, Bhattacharyya MK. Inhibition of phosphoinositide-specific phospholipase $\mathrm{C}$ results in the induction of pathogenesis-related genes in soybean. Plant Biol (Stuttg) 2004;6:664-72.

[186] Shi J, Gonzales RA, Bhattacharyya MK. Characterization of a plasma membrane-associated phosphoinositide-specific phospholipase C from soybean. Plant J 1995;8:381-90.

[187] Kopka J, Pical C, Gray JE, Müller-Röber B. Molecular and enzymatic characterization of three phosphoinositide-specific phospholipase C isoforms from potato. Plant Physiol 1998;116:239-50.

[188] Liu HT, Liu YY, Pan QH, Yang HR, Zhan JC, Huang WD. Novel interrelationship between salicylic acid, abscisic acid, and $\mathrm{PIP}_{2}$-specific phospholipase $\mathrm{C}$ in heat acclimation-induced thermotolerance in pea leaves. J Exp Bot 2006;57:3337-47.

[189] Georges F, Das S, Ray H, Bock C, Nokhrina K, Kolla VA, et al. Over-expression of Brassica napus phosphatidylinositol-phospholipase $\mathrm{C} 2$ in canola induces significant changes in gene expression and phytohormone distribution patterns, enhances drought tolerance and promotes early flowering and maturation. Plant Cell Environ 2009;32:1664-81.

[190] Kim YJ, Kim JE, Lee JH, Lee MH, Jung HW, Bahk YY, et al. The Vr-PLC3 gene encodes a putative plasma membrane-localized phosphoinositide-specific phospholipase $\mathrm{C}$ whose expression is induced by abiotic stress in mung bean (Vigna radiata L.). FEBS Lett 2004;556:127-36.

[191] Huang CH, Crain RC. Phosphoinositide-specific phospholipase C in oat roots: association with the actin cytoskeleton. Planta 2009;230:925-33.

[192] Pan YY, Wang X, Ma LG, Sun DY. Characterization of phosphatidylinositol-specific phospholipase C (PI-PLC) from Lilium daviddi pollen. Plant Cell Physiol 2005; 46:1657-65.

[193] Wang CR, Yang AF, Yue GD, Gao Q, Yin HY, Zhang JR. Enhanced expression of phospholipase C 1 (ZmPLC1) improves drought tolerance in transgenic maize. Planta 2008;227:1127-40.

[194] Repp A, Mikami K, Mittmann F, Hartmann E. Phosphoinositide-specific phospholipase C is involved in cytokinin and gravity responses in the moss Physcomitrella patens. Plant $\mathrm{J}$ 2004;40:250-9.

[195] Mikami K, Repp A, Graebe-Abts E, Hartmann E. Isolation of cDNAs encoding typical and novel types of phosphoinositide-specific phospholipase $\mathrm{C}$ from the moss Physcomitrella patens. J Exp Bot 2004;55:1437-9.

[196] Tasma IM, Brendel V, Whitham SA, Bhattacharyya MK. Expression and evolution of the phosphoinositide-specific phospholipase C gene family in Arabidopsis thaliana. Plant Physiol 
Biochem 2008;46:627-37.

[197] Liu HT, Huang WD, Pan QH, Weng FH, Zhan JC, Liu Y, et al. Contributions of $\mathrm{PIP}_{2}$-specific-phospholipase $\mathrm{C}$ and free salicylic acid to heat acclimation-induced thermotolerance in pea leaves. J Plant Physiol 2006;163:405-16.

[198] Zhai S, Sui Z, Yang A, Zhang J. Characterization of a novel phosphoinositide-specific phospholipase C from Zea mays and its expression in Escherichia coli. Biotechnol Lett 2005;27:799-804.

[199] Kouchi Z, Shikano T, Nakamura Y, Shirakawa H, Fukami K, Miyazaki S. The role of EF-hand domains and $\mathrm{C} 2$ domain in regulation of enzymatic activity of phospholipase $\mathrm{C} \zeta$. J Biol Chem 2005;280:21015-21.

[200] Nomikos M, Elgmati K, Theodoridou M, Calver BL, Nounesis G, Swann K, et al. Phospholipase $\mathrm{C} \zeta$ binding to PtdIns(4,5) $\mathrm{P}_{2}$ requires the $\mathrm{XY}$-linker region. J Cell Sci 2011;124:2582-90.

[201] Rupwate SD, Rajasekharan R. Plant phosphoinositide-specific phospholipase C: an insight. Plant Signal Behav 2012;7:1281-3.

[202] Nakamura K, Sano H. A plasma-membrane linker for the phosphoinositide-specific phospholipase C in tobacco plants. Plant Signal Behav 2009;4:26-9.

[203] Otterhag L, Sommarin M, Pical C. N-terminal EF-hand-like domain is required for phosphoinositide-specific phospholipase C activity in Arabidopsis thaliana. FEBS Lett 2001;497:165-70.

[204] McMurray WC, Irvine RF. Phosphatidylinositol 4,5-bisphosphate phosphodiesterase in higher plants. Biochem J 1988;249:877-81.

[205] Drøbak BK. The plant phosphoinositide system. Biochem J 1992;288:697-712.

[206] Melin PM, Pical C, Jergil B, Sommarin M. Polyphosphoinositide phospholipase C in wheat root plasma membranes. Partial purification and characterization. Biochim Biophys Acta 1992;1123:163-9.

[207] Cockcroft S, Thomas GM. Inositol-lipid-specific phospholipase C isoenzymes and their differential regulation by receptors. Biochem J 1992;288:1-14.

[208] Feng JF, Rhee SG, Im MJ. Evidence that phospholipase $\delta 1$ is the effector in the $\mathrm{G}_{\mathrm{h}}$ (transglutaminase II)-mediated signaling. J Biol Chem 1996;271:16451-4.

[209] Misra S, Wu Y, Venkataraman G, Sopory SK, Tuteja N. Heterotrimeric G-protein complex and G-protein-coupled receptor from a legume (Pisum sativum): role in salinity and heat stress and cross-talk with phospholipase C. Plant J 2007;51:656-69.

[210] Nühse TS, Stensballe A, Jensen ON, Peck SC. Phosphoproteomics of the Arabidopsis plasma membrane and a new phosphorylation site database. Plant Cell 2004;16:2394-405.

[211] Cho MH, Tan Z, Erneux C, Shears SB, Boss WF. The effects of mastoparan on the carrot cell plasma membrane polyphosphoinositide phospholipase C. Plant Physiol 1995;107:845-56.

[212] De Los Santos-Briones C, Cárdenas L, Estrada-Navarrete G, Santana O, Minero-García Y, Quinto C, et al. GTP $\gamma \mathrm{S}$ antagonizes the mastoparan-induced in vitro activity of PIP-phospholipase C from symbiotic root nodules of Phaseolus vulgaris. Physiol Plant 2009;135:237-45.

[213] Delage E, Ruelland E, Zachowski A, Puyaubert J. Eat in or take away? How phosphatidylinositol 4-kinases feed the phospholipase C pathway with substrate. Plant Signal 
Behav 2012;7:1197-9.

[214] Rupwate SD, Rajasekharan R. C2 domain is responsible for targeting rice phosphoinositide specific phospholipase C. Plant Mol Biol 2012;78:247-58.

[215] Novotna Z, Valentova O, Martinec J, Feltl T, Nokhrina K. Study of phospholipases D and C in maturing and germinating seeds of Brassica napus. Biochem Soc Trans 2000;28:817-8.

[216] Dowd PE, Coursol S, Skirpan AL, Kao TH, Gilroy S. Petunia phospholipase C1 is involved in pollen tube growth. Plant Cell 2006;18:1438-53.

[217] Qin W, Pappan K, Wang X. Molecular heterogeneity of phospholipase D (PLD). Cloning of PLD $\gamma$ and regulation of plant PLD $\gamma,-\beta$, and $-\alpha$ by polyphosphoinositides and calcium. J Biol Chem 1997;272:28267-73.

[218] Monteiro D, Liu Q, Lisboa S, Scherer GE, Quader H, Malhó R. Phosphoinositides and phosphatidic acid regulate pollen tube growth and reorientation through modulation of $\left[\mathrm{Ca}^{2+}\right]_{\mathrm{c}}$ and membrane secretion. J Exp Bot 2005;56:1665-74.

[219] Perera IY, Heilmann I, Boss WF. Transient and sustained increases in inositol 1,4,5-trisphosphate precede the differential growth response in gravistimulated maize pulvini. Proc Natl Acad Sci USA 1999;96:5838-43.

[220] Perera IY, Heilmann I, Chang SC, Boss WF, Kaufman PB. A role for inositol 1,4,5-trisphosphate in gravitropic signaling and the retention of cold-perceived gravistimulation of oat shoot pulvini. Plant Physiol 2001;125:1499-507.

[221] Lu YT, Hidaka H, Feldman LJ. Characterization of a calcium/calmodulin-dependent protein kinase homolog from maize roots showing light-regulated gravitropism. Planta 1996;199:18-24.

[222] Tan X, Calderon-Villalobos LI, Sharon M, Zheng C, Robinson CV, Estelle M, et al. Mechanism of auxin perception by the TIR1 ubiquitin ligase. Nature 2007;446:640-5.

[223] Li L, He Y, Wang Y, Zhao S, Chen X, Ye T, et al. Arabidopsis PLC2 is involved in auxin-modulated reproductive development. Plant J 2015. Epub 2015 Sep 4.

[224] Gao K, Liu YL, Li B, Zhou RG, Sun DY, Zheng SZ. Arabidopsis thaliana phosphoinositide-specific phospholipase C isoform 3 (AtPLC3) and AtPLC9 have an additive effect on thermotolerance. Plant Cell Physiol 2014;55:1873-83.

[225] Gonorazky G, Ramirez L, Abd-El-Haliem A, Vossen JH, Lamattina L, ten Have A, et al. The tomato phosphatidylinositol-phospholipase C2 (SIPLC2) is required for defense gene induction by the fungal elicitor xylanase. J Plant Physiol 2014;171:959-65.

[226] Parre E, Ghars MA, Leprince AS, Thiery L, Lefebvre D, Bordenave M, et al. Calcium signaling via phospholipase $\mathrm{C}$ is essential for proline accumulation upon ionic but not nonionic hyperosmotic stresses in Arabidopsis. Plant Physiol 2007;144:503-12.

[227] Lemtiri-Chlieh F, MacRobbie EA, Brearley CA. Inositol hexakisphosphate is a physiological signal regulating the $\mathrm{K}^{+}$-inward rectifying conductance in guard cells. Proc Natl Acad Sci USA 2000;97:8687-92.

[228] Munnik T, Irvine RF, Musgrave A. Phospholipid signalling in plants. Biochim Biophys Acta 1998;1389:222-72.

[229] Munnik T, Irvine RF, Musgrave A. Rapid turnover of phosphatidylinositol 3-phosphate in the green alga Chlamydomonas eugametos: signs of a phosphatidylinositide 3-kinase signalling pathway in lower plants? Biochem J 1994;298:269-73.

[230] Munnik T. PI-PLC: phosphoinositide-phospholipase C in plant signaling. In: Wang X, editor. 
Phospholipases in plant signaling, Signaling and communication in plants, Berlin, Heidelberg: Springer; 2014, p. 27-54.

[231] Shin JJ, Loewen CJ. Putting the $\mathrm{pH}$ into phosphatidic acid signaling. BMC Biol 2011;9:85.

[232] Vu H, Tamura P, Galeva NA, Chaturvedi R, Williams TD, Wang X, et al. Direct infusion tandem mass spectral profiling of oxylipin-containing Arabidopsis thaliana phospholipids and galactolipids reveals varied patterns in response to different stressors. Plant Physiol 2012;158:324-39.

[233] den Hartog M, Musgrave A, Munnik T. Nod factor-induced phosphatidic acid and diacylglycerol pyrophosphate formation: a role for phospholipase $\mathrm{C}$ and $\mathrm{D}$ in root hair deformation. Plant J 2001;25:55-65.

[234] De Jong CF, Laxalt AM, Bargmann BO, De Wit PJ, Joosten MH, Munnik T. Phosphatidic acid accumulation is an early response in the Cf-4/Avr4 interaction. Plant J 2004;39:1-12.

[235] Nakano M, Nishihara M, Yoshioka H, Takahashi H, Sawasaki T, Ohnishi K, et al. Suppression of DS1 phosphatidic acid phosphatase confirms resistance to Ralstonia solanacearum in Nicotiana benthamiana. PLoS One 2013;8:e75124.

[236] Arisz SA, Munnik T. Distinguishing phosphatidic acid pools from de novo synthesis, PLD, and DGK. Methods Mol Biol 2013;1009:55-62.

[237] Arisz SA, Testerink C, Munnik T. Plant PA signaling via diacylglycerol kinase. Biochim Biophys Acta 2009;1791:869-75.

[238] den Hartog M, Verhoef N, Munnik T. Nod factor and elicitors activate different phospholipid signaling pathways in suspension-cultured alfalfa cells. Plant Physiol 2003;132:311-17.

[239] Testerink C, Larsen PB, van der Does D, van Himbergen JA, Munnik T. Phosphatidic acid binds to and inhibits the activity of Arabidopsis CTR1. J Exp Bot 2007;58:3905-14.

[240] Guo L, Mishra G, Taylor K, Wang X. Phosphatidic acid binds and stimulates Arabidopsis sphingosine kinases. J Biol Chem 2011;286:13336-45.

[241] Huang S, Gao L, Blanchoin L, Staiger CJ. Heterodimeric capping protein from Arabidopsis is regulated by phosphatidic acid. Mol Biol Cell 2006;17:1946-58.

[242] Pleskot R, Pejchar P, Žárský V, Staiger CJ, Potocký M. Structural insights into the inhibition of actin-capping protein by interactions with phosphatidic acid and phosphatidylinositol (4,5)-bisphosphate. PLoS Comput Biol 2012;8:e1002765.

[243] Testerink C, Dekker HL, Lim ZY, Johns MK, Holmes AB, Koster CG, et al. Isolation and identification of phosphatidic acid targets from plants. Plant J 2004;39:527-36.

[244] Anthony RG, Henriques R, Helfer A, Mészáros T, Rios G, Testerink C, et al. A protein kinase target of a PDK1 signalling pathway is involved in root hair growth in Arabidopsis. EMBO J 2004;23:572-81.

[245] Li J, Henty-Ridilla JL, Huang S, Wang X, Blanchoin L, Staiger CJ. Capping protein modulates the dynamic behavior of actin filaments in response to phosphatidic acid in Arabidopsis. Plant Cell 2012;24:3742-54.

[246] Li J, Henty-Ridilla JL, Staiger BH, Day B, Staiger CJ. Capping protein integrates multiple MAMP signalling pathways to modulate actin dynamics during plant innate immunity. Nat Commun 2015;6:7206.

[247] Takemoto D, Hardham AR. The cytoskeleton as a regulator and target of biotic interactions in plants. Plant Physiol 2004;136:3864-76. 
[248] Fionn M, Steven AA, Henk L, Gertjan K, Chris G, Michel AH, et al. Identification of novel candidate phosphatidic acid-binding proteins involved in the salt-stress response of Arabidopsis thaliana roots. Biochem J 2013;450:573-81.

[249] Loewen CJ, Gaspar ML, Jesch SA, Delon C, Ktistakis NT, Henry SA, et al. Phospholipid metabolism regulated by a transcription factor sensing phosphatidic acid. Science 2004;304:1644-7.

[250] Yao H, Wang G, Guo L, Wang X. Phosphatidic acid interacts with a MYB transcription factor and regulates its nuclear localization and function in Arabidopsis. Plant Cell 2013;25:5030-42.

[251] Yao H, Wang G, Wang X. Nuclear translocation of proteins and the effect of phosphatidic acid. Plant Signal Behav 2014;9:e977711.

[252] van den Brink-van der Laan E, Killian JA, de Kruijff B. Nonbilayer lipids affect peripheral and integral membrane proteins via changes in the lateral pressure profile. Biochim Biophys Acta 2004;1666:275-88.

[253] Kooijman EE, Chupin V, de Kruijff B, Burger KN. Modulation of membrane curvature by phosphatidic acid and lysophosphatidic acid. Traffic 2003;4:162-74.

[254] Ohlrogge J, Browse J. Lipid biosynthesis. Plant Cell 1995;7:957-70.

[255] Wang Z, Xu C, Benning C. TGD4 involved in endoplasmic reticulum-to-chloroplast lipid trafficking is a phosphatidic acid binding protein. Plant $\mathrm{J}$ 2012;70:614-23.

[256] Dubots E, Audry M, Yamaryo Y, Bastien O, Ohta H, Breton C, et al. Activation of the chloroplast monogalactosyldiacylglycerol synthase MGD1 by phosphatidic acid and phosphatidylglycerol. J Biol Chem 2010;285:6003-11.

[257] Gibellini F, Smith TK. The Kennedy pathway-De novo synthesis of phosphatidylethanolamine and phosphatidylcholine. IUBMB Life 2010;62:414-28.

[258] Wang X, Su Y, Liu Y, Kim S, Fanella B. Phosphatidic acid as lipid messenger and growth regulators in plants. In: Wang X, editor. Phospholipases in plant signaling, Signaling and communication in plants, Berlin, Heidelberg: Springer; 2014, p. 69-92.

[259] Eastmond PJ, Quettier AL, Kroon JT, Craddock C, Adams N, Slabas AR. Phosphatidic acid phosphohydrolase 1 and 2 regulate phospholipid synthesis at the endoplasmic reticulum in Arabidopsis. Plant Cell 2010;22:2796-811.

[260] Craddock CP, Adams N, Bryant FM, Kurup S, Eastmond PJ. phosphatidic acid phosphohydrolase regulates phosphatidylcholine biosynthesis in Arabidopsis by phosphatidic acid-mediated activation of CTP:phosphocholine cytidylyltransferase activity. Plant Cell. 2015;27:1251-64.

[261] Sirover MA. New insights into an old protein: the functional diversity of mammalian glyceraldehyde-3-phosphate dehydrogenase. Biochim Biophys Acta 1999;1432:159-84.

[262] Nicholls C, Pinto AR, Li H, Li L, Wang L, Simpson R, et al. Glyceraldehyde-3-phosphate dehydrogenase (GAPDH) induces cancer cell senescence by interacting with telomerase RNA component. Proc Natl Acad Sci USA 2012;109:13308-13.

[263] Choi SY, Huang P, Jenkins GM, Chan DC, Schiller J, Frohman MA. A common lipid links Mfn-mediated mitochondrial fusion and SNARE-regulated exocytosis. Nat Cell Biol 2006;8:1255-62. 
Figure Legends

Figure 1. Reactions of different phospholipases and hydrolytic products (in parentheses). PLD, phospholipase D; PLC, phospholipase C; PLA 1 and PLA 2 , phospholipase $\mathrm{A}_{1}$ and $\mathrm{A}_{2}$, respectively; PA, phosphatidic acid; DAG, diacylglycerol; 1-LPL, 1-lysophospholipid; 2-LPL, 2-LPL; FFA, free fatty acid; X, free head group, such as choline; P-X, phosphorylated head group.

Figure 2. Arabidopsis PLD domain structures and distinguishable biochemical properties. PC, phosphatidylcholine; PE, phosphatidylethanolamine; $\mathrm{PIP}_{2}$, phosphatidylinositol 4,5-bisphosphate

Figure 3. Distinguishable functions of PLDa1 and PLDo in regulating ROS production and response under water deficits and in response to ABA. Activation of PLD $\alpha 1$ preferably hydrolyzes PC to produce PA that tethers ABI1 to the plasma membrane and PA also binds and activates NADPH oxidase activity that generates reactive oxygen species (ROS). $\mathrm{ROS} \mathrm{H}_{2} \mathrm{O}_{2}$ inactivates the cytosolic glycolytic enzyme glyceraldehyde-3-phosphate dehydrogenases (GAPC). GAPC ${ }_{\text {ox }}$ refers to oxidized, catalytically inactive GAPC that interacts with PLD $\delta$ and promotes PLD $\delta$ activity. PLD $\delta$ hydrolyzes PE. GAPC $_{\text {red }}$ refers to reduced, active GAPC that converts glyceraldehyde-3-phosphate (G3P) to 1,3-bisphosphoglycerate (1,3-bisPG) with NADH production. Solid arrows indicate established links and dashed arrows denote putative links. This model depicts only the known targets of PLD/PA in the ABA-mediated stomatal closure; other ABA regulators are not included in this model. Adopted from Guo et al., 2012.

Figure 4. Proposed impacts of PLDs and PA on ROS production and plant defense response. Microbe associated molecular patterns (MAMPs) are recognized by pattern recognition receptors (PRRs) or pathogens-secreted effectors are recognized by cellular R proteins. The plant-microbe interaction leads to activation of specific PLDs. PLD $\alpha 1$ interacts with GTP-binding protein $\alpha$-subunit that is activated by pathogen infection to mediate defense response. PLD $\alpha 1$ hydrolyzes PC to produce PA that binds and activates NADPH oxidase to produce reactive oxygen species (ROS). ROS activates PLD $\delta$ that hydrolyzes PE to produce PA. PA stimulates mitogen-activated protein kinase (MPK6) and phosphoinositide-dependent kinase 1 (PDK1) in defense signaling cascades. PA also modulates the interaction of 14-3-3 with $\mathrm{PM} \mathrm{H}^{+}$-ATPase that alters membrane potentials and nutrient transport. PLD-produced PA interacts with microtubule-associated proteins (MAP65-1) to modify cytoskeleton dynamics in response to pathogen infections.

Figure 5. Potential effects of PLD $\zeta$ s and PA on plant hormone signaling and MAMP perception and downstream defense responses. PLD $\zeta-P A$ can target on protein phosphatase $2 \mathrm{~A}$ (PP2A) to regulate phosphor-status of FLS2 (or BRI1)-BAK1 complexes to affect the perception of either MAMP signals such as flagellin or hormone BRs on the plasma membrane (PM). PA binds to and represses cytosolic PP2A to regulate BZR1 phosphorylation. PA mediates hormone signaling by regulating auxin efflux transporter PIN2, JA and SA. PA derived from PLD $\zeta$ s may also target on protein kinase cascade to regulate ROS signaling, and other hormone signaling networks involved in plant development and in plant defense responses. 
Figure 6. Proposed involvement of PLD and PA in membrane vesicle trafficking. PLD is activated by binding of phosphoinositide lipids such as PIP $_{2}$ and generates PA. The accumulation of negatively charged, cone-shaped PA promotes membrane curvature formation and meanwhile PA recruits the attachment of various coat proteins, such as ARF, Rho GTPase, SNARE proteins to the membrane vesicles. Vesicle trafficking and membrane fusion and fission are dependent of cytoskeleton dynamics. PLD and /or PA facilitate vesicle trafficking by directly interacting with actin or tubulins and by regulating activities of actin- and tubulin /microtubule-associated proteins such as AtCP and MAP65-1, which regulate actin and tubulin polymerization (+) or depolymerization (-) to induce the cytoskeleton dynamics.

Figure 7. Production of $P A$ and DAG by different reactions and interconversion of $P A$ and DAG by phosphorylation and dephosphorylation. Shown below is biological functions of PA and DAG produced that have been experimentally identified. PC, phosphatidylcholine; PE, phosphatidylethanolamine; PIPs, phosphatidylinositol polyphosphates; PA, phosphatidic acid; DAG, diacylglycerol; LPA, lysophosphatidic acid; G3P, glycerol-3-phosphate; IPx, inositol polyphosphates; PLD, phospholipase D; NPC, non-specific phospholipase C; PI-PLC, PI-specific phospholipase C; PAP, PA phosphatase; DGK, DAG kinase; GPAT, G3P acyltransferase; LPAT, LPA acyltransferase

Figure 8. PI-PLC domain structures and potential functions in plants. In response to the stimuli, PI-PLC is activated to produce DAG and $\mathrm{IP}_{3}$. In plants, DAG target has not been identified, and $\mathrm{IP}_{3}$ receptor remains elusive. DAG can be phosphorylated into $\mathrm{PA}$ and $\mathrm{IP}_{3}$ is phosphorylated to $\mathrm{IP}_{6}$. At the same time, the activation of PI-PLC also results in the alteration of substrates such as $\mathrm{PI}(4,5) \mathrm{P}_{2}$ and $\mathrm{PI} 4 \mathrm{P}$, which are involved in vesicle trafficking and tip growth, and membrane lipid remodeling.

Figure 9. PA effects on protein intracellular translocation between nucleus and cytoplasm. PA can promote or inhibit protein localization to the nucleus, depending on the specific protein. PA interacts with a MYB transcription factor and the interaction is necessary for WER's nuclear localization to regulate the root hair development in Arabidopsis. PA tethers its binding protein ABI1 to the plasma membrane, decreasing ABA INSENSTIVE 1 (ABI1) translocation into the nucleus. PtdIns(5)P promotes translocation of antioxidant protein 1 (ATX1), a histone 3 lysine 4 (H3K4me3) trimethyltransferase, from the nucleus to the cytoplasm to regulate gene expression. In Saccharomyces cerevisiae, PA in ER binds to the transcriptional repressor OVERPRODUCER OF INOSITOL PROTEIN 1 (Opilp) and keeps it out of the nucleus to regulate phospholipid metabolism. Adopted from Yao et al., 2014 